Rowan University

Rowan Digital Works

7-19-2013

\title{
Identification and Distribution of Projections from Monoaminergic and cholinergic nuclei to Functionally Differentiated Subregions of Prefrontal Cortex
}

\author{
Daniel Chandler \\ Rowan University School of Osteopathic Medicine \\ Carolyn Lamperski \\ Drexel University \\ Barry Waterhouse \\ Rowan University School of Osteopathic Medicine
}

Follow this and additional works at: https://rdw.rowan.edu/som_facpub

Part of the Anatomy Commons, Biology Commons, Cell Biology Commons, Cellular and Molecular Physiology Commons, and the Neuroscience and Neurobiology Commons

\section{Recommended Citation}

Chandler DJ, Lamperski CS, Waterhouse BD. Identification and Distribution of Projections from Monoaminergic and cholinergic nuclei to Functionally Differentiated Subregions of Prefrontal Cortex. Brain Res. 2013 Jul 19;1522:38-58. Epub 2013 May 7. doi: 10.1016/j.brainres.2013.04.057. PMID: 23665053. PMCID: PMC3811940. 


\title{
Identification and distribution of projections from monoaminergic and cholinergic nuclei to functionally differentiated subregions of prefrontal cortex
}

\author{
Daniel J. Chandler, Carolyn S. Lamperski, and Barry D. Waterhouse* \\ Department of Neurobiology and Anatomy, Drexel University College of Medicine, 2900 Queen \\ Lane, Philadelphia, PA 19128, United States
}

\begin{abstract}
The prefrontal cortex (PFC) is implicated in a variety of cognitive and executive functions and is composed of several distinct networks, including anterior cingulate cortex (ACC), medial prefrontal cortex (mPFC), and orbitofrontal cortex (OFC). These regions serve dissociable cognitive functions, and are heavily innervated by acetylcholine, dopamine, serotonin and norepinephrine systems. In this study, fluorescently labeled retrograde tracers were injected into the ACC, mPFC, and OFC, and labeled cells were identified in the nucleus basalis (NB), ventral tegmental area (VTA), dorsal raphe nucleus (DRN) and locus coeruleus (LC). DRN and LC showed similar distributions of retrogradely labeled neurons such that most were single labeled and the largest population projected to mPFC. VTA showed a slightly greater proportion of double and triple labeled neurons, with the largest population projecting to OFC. NB, on the other hand, showed mostly double and triple labeled neurons projecting to multiple subregions. Therefore, subsets of VTA, DRN and LC neurons may be capable of modulating individual prefrontal subregions independently, whereas NB cells may exert a more unified influence on the three areas simultaneously. These findings emphasize the unique aspects of the cholinergic and monoaminergic projections to functionally and anatomically distinct subregions of PFC.
\end{abstract}

\section{Keywords}

Nucleus basalis; Ventral tegmental area; Dorsal Raphe nucleus; Locus coeruleus; Prefrontal cortex; Retrograde tracing

\section{Introduction}

The PFC is associated with several higher order cognitive functions such as rule-based and goal-directed behaviors, working memory, decision-making and reward seeking (Brown and Bowman, 2002; Dalley et al., 2004; Furuyashiki and Gallagher, 2007; Fuster, 2000; Ongur and Price, 2000; Passetti et al., 2002; Robbins, 2000). The connectivity and intrinsic organization of this region of the brain is optimal for its role in abstract behavioral and executive processes (Dalley et al., 2004; Fuster, 2000; Hoover and Vertes, 2007; Passetti et al., 2002). The PFC is composed of several anatomically and functionally distinct subregions, including OFC, mPFC, and ACC. In the rodent, OFC is implicated in reversal

“Corresponding author. Fax: +1 215843 9082. Barry.waterhouse@drexelmed.edu, waterhouse@ drexelmed.edu (B.D. Waterhouse). Appendix A. Supporting information

Supplementary data associated with this article can be found in the online version at http://dx.doi.org/10.1016/j.brainres.2013.04.057. 
learning and lower order sensory discriminations (Dalley et al., 2004; Furuyashiki and Gallagher, 2007; Kolb et al., 2004; Murray et al., 2007; Rushworth et al., 2009; Schoenbaum et al., 2007; Sul et al., 2010), while mPFC is involved in higher order sensory-based discriminations, behavioral flexibility and sustained attention (Dalley et al., 2004; Floresco et al., 2008; McGaughy et al., 2008; Newman et al., 2008), and ACC is implicated in behavioral impulse control and regulation (Bussey et al., 1997). Importantly, functional, and to a lesser degree, anatomical, homology exists between rodent and human PFC (Dalley et al., 2004). These regions are each unique in their afferent and efferent connections (Dalley et al., 2004; Hoover and Vertes, 2007); however, several ascending neuromodulatory pathways all converge in these regions to regulate network activity. The purpose of this study was to identify the organization and distribution of cells in NB, VTA, DRN and LC that project to functionally and anatomically distinct subregions of PFC.

The NB is the primary source of cholinergic input to the cerebral cortex (Sarter and Bruno, 2000; Wenk, 1997) and has been implicated in arousal, learning, attention and memory (McGaughy et al., 2000; McGaughy and Sarter, 1998, 1999; Nieto-Escamez et al., 2002; Sarter and Bruno, 2000; Wenk, 1997). A rough topography has been identified in the primate analog of NB, nucleus basalis of Meynert, such that ante-romedial portions of the nucleus project to the medial surface of the cortex, anterolateral regions project to frontal and parietal cortices and amygdala, intermediate regions project to prefrontal, insular and posterior parietal cortices, and caudal portions project to the superior and temporal cortex (Pang et al., 1993). This nucleus is less well defined in rodent and its cholinergic projection neurons are more scattered (Sarter and Bruno, 2000; Wenk, 1997); however, it similarly stains intensely for cholinergic markers, is situated in roughly the same region of the brain, and has also been implicated in the modulation of higher order cognitive processes (Lehmann et al., 1980; McGaughy and Sarter, 1998; 1999; Nieto-Escamez et al., 2002; Sarter and Bruno, 2000; Wenk, 1997). This group of cells has also been given the designation Ch4 by Mesulam and colleagues (Mesulam et al., 1983).

The VTA is similarly involved in several higher order cognitive processes such as reward seeking and working memory (Carr et al., 1999; Chambers et al., 2010; Greene, 2006; Grimm et al., 2004; Li et al., 2009; Pang et al., 1993; Schultz, 1998; Vucetic et al., 2010; Wang et al., 2010). Previous accounts of the VTA projection system indicate that its efferents do not collateralize extensively (Loughlin and Fallon, 1984; Sobel and Corbett, 1984). Furthermore, these cells have been shown to be topographically ordered with respect to their projection targets (Beckstead et al., 1979; Carter and Fibiger, 1977; Fallon et al., 1978; Fallon and Loughlin, 1982; Fallon and Moore, 1978a, 1978b; Loughlin and Fallon, 1984; Sobel and Corbett, 1984) such that medial cell groups innervate more medial and rostral structures, while laterally positioned cells innervate more lateral and caudal structures (Loughlin and Fallon, 1984).

The DRN is one of several midbrain serotonergic nuclei, and the primary source of serotonin to the forebrain. It is involved in the regulation of mood, sleep and waking cycles (Mamounas and Molliver, 1988; Moore and Halaris, 1975; Moore et al., 1978; O'Hearn and Molliver, 1984). The DRN displays a rough topographical organization (Abrams et al., 2004; Vertes, 1991) such that more rostral structures are innervated by more rostral portions of DRN whereas caudal structures receive input from more caudal clusters of cells (Abrams et al., 2004). Cortical structures receive input primarily from cells located along the midline and dorsal to the medial longitudinal fasciculus, whereas subcortical structures receive projections from cells located in the lateral wings (Kirifides et al., 2001; O'Hearn and Molliver, 1984; Van Bockstaele et al., 1993; Villar et al., 1988; Waterhouse et al., 1986, 1993). Furthermore, it has been shown that DRN cells collateralize more extensively to forebrain structures than do those projecting from VTA (Sobel and Corbett, 1984; Van 
Bockstaele et al., 1993) and that axons emanating from individual DRN neurons tend to send collaterals to multiple functionally related targets simultaneously (Abrams et al., 2004; Simpson et al., 1997; Van Bockstaele et al., 1993). The projections from DRN to various subregions of PFC have not been characterized (Tables 1-4).

The LC is the only source of norepinephrine-containing fibers to the PFC (Berridge and Waterhouse, 2003; Sara, 2009) and, in addition, exerts a widespread influence on neuronal circuitries involved in sensory processing, motor behavior, arousal and cognitive processes (Berridge and Waterhouse, 2003; Cain et al., 2011; Devilbiss et al., 2006; Devilbiss and Waterhouse, 2000, 2004; Hurley et al., 2004; McGaughy et al., 2008; McGaughy and Sarter, 1998; Moxon et al., 2007; Newman et al., 2008; Sara, 2009). Previous reports that describe LC anatomy suggest that this nucleus is highly divergent with only minimal efferent topographic organization (Fallon and Loughlin, 1982; Loughlin et al., 1982; Waterhouse et al., 1983, 1993), although some LC cells send axon collaterals to multiple target structures along the same sensory pathway (Simpson et al., 1997, 1999, 2006). However, the nature of the projection from LC to the major subregions of PFC subregions has not yet been explored.

The purpose of the present study was to examine in greater detail the projections from NB, VTA, DRN and LC to OFC, mPFC and ACC with particular focus on efferent topographic relationships and patterns of axonal collateralization within these projection systems. As all of these modulatory pathways are involved in complex behavioral and cognitive processes, become dysfunctional in many forms of neuropsychiatric and neurodegenerative disease, and are targeted by many classes of CNS drugs, it is critically important to understand the efferent connectivity of the neurons comprising these pathways. A preliminary report describing the organizing principles of the LC- and NB-PFC projections has appeared previously in a theoretical review article (Chandler and Waterhouse, 2012); only new analyses of the data related to these nuclei are presented here.

\section{Results}

Data are reported from 9 of 10 animals where injections were confirmed to be within the anatomical boundaries of OFC, mPFC and ACC. Fig. 1A shows representative fluorescent photomicrographs of injected PFC subregions from a single animal and the extent of tracer diffusion. All subsequent representative photomicrographs were generated from the same animal. Fig. 1B shows the boundaries of the largest (lighter color) and smallest (darker color) injections in each representative section (taken from all 9 animals), and the overlap between these areas (hatched areas). Curves in Fig. 1C represent the mean area filled in each section as a function of its distance from bregma as defined by Paxinos and Watson (1997). The area under each curve is equal to the estimated volume filled shown in Fig. 1D. A mixed design ANOVA was performed to compare these values, and it was found that a significantly greater volume of OFC was filled than $\mathrm{mPFC}$ by tracer injection across all animals $(p<0.05)$. The vast majority of all retrogradely labeled cells were identified ipsilateral to the injection sites; as such, all subsequent analyses consider only the ipsilateral component of these projection systems.

\subsection{Nucleus basalis}

In two brains, the quality of the tissue encompassing NB was compromised during sectioning, thus making it difficult to reliably identify the nucleus and analyze data from these cases. Therefore the data reported for NB are representative of seven animals. Six hundred and eighty two retrogradely labeled putative cholinergic NB cells were identified across all animals. Representative low and high power images of retrogradely labeled putative cholinergic NB cells are shown in Fig. 2. Ninety two cells were found to project to 
OFC, 112 cells to mPFC, and 67 cells to ACC. Ninety four cells were found to collateralize to both OFC and mPFC, 68 cells collateralized to OFC and ACC, and 100 cells collateralized to $\mathrm{mPFC}$ and ACC. The remaining 149 cells projected to all three regions (Fig. 3B). A chi square goodness of fit test was performed to determine if populations within the nucleus differed in size and was found to be highly significant $\left[X^{2}(6, n=682)=48.461\right.$, $p=0.000]$.

The rostrocaudal distribution (Fig. 3A) of retrogradely labeled cells in NB shows that prefrontal projection neurons tended to cluster in the rostral portion of the nucleus. The median section is defined as the section to which half of all retrogradely labeled cells within a nucleus are rostral and the other half are caudal. Therefore, its position serves as an indicator of clustering in the rostrocaudal dimension. The average distance \pm SEM between the most rostral point of $\mathrm{NB}(-0.8 \mathrm{~mm}$ AP from bregma) and the median section were as follows: OFC: $514.29 \pm 61.21 \mu \mathrm{m}$; mPFC: $437.14 \pm 36.36 \mu \mathrm{m}$; ACC: $462.86 \pm 53.53 \mu \mathrm{m}$; OFC+mPFC: $462.86 \pm 66.39 \mu \mathrm{m}$; OFC+ACC: $334.29 \pm 25.71 \mu \mathrm{m}$; mPFC+ACC: $411.43 \pm$ $33.20 \mu \mathrm{m}$; OFC+mPFC +ACC: $514.29 \pm 46.95 \mu \mathrm{m}$ (Fig. 3C). These all occurred within the rostral-most $25 \%$ of the nucleus, and the populations extended less than $50 \%$ of its rostrocaudal length. A Friedman test comparing the distance to the median sections for the various populations was found to be nonsignificant $\left[X^{2}(6, n=7)=9.873, p=0.130\right]$.

\subsection{Ventral tegmental area}

Representative low and high power images of retrogradely labeled VTA cells are shown in Fig. 4. A total of 1489 retrogradely labeled VTA cells were counted from 9 animals. Six hundred and fifty six cells were found to project to OFC, 376 cells projected to $\mathrm{mPFC}$, and 279 cells projected to ACC. Fourty six cells collateralized to both OFC and mPFC, 43 cells collateralized to OFC and ACC, and 44 cells collateralized to MPFC and ACC. The remaining 45 triple labeled cells projected to all three regions simultaneously (Fig. 5B). A chi square goodness of fit test was performed to determine if populations within the nucleus differed in size and was found to be highly significant $\left(X^{2}(6, n=1496)=1701.709, p=\right.$ $0.000)$.

The rostrocaudal distribution (Fig. 5A) of retrogradely labeled cells in the VTA showed that the highest number of cells were located in the rostral portion of the nucleus. Retrogradely labeled cells also tended to cluster within the medial zone of the nucleus. The average distance \pm SEM between the most rostral point of VTA ( $-5.2 \mathrm{~mm} \mathrm{AP} \mathrm{from} \mathrm{bregma)} \mathrm{and} \mathrm{the}$ median section for each population of projection cells were as follows: OFC: $760.00 \pm 40.00$ $\mu \mathrm{m}$; mPFC: $800.00 \pm 60.83 \mu \mathrm{m}$; ACC: $860.00 \pm 65.57 \mu \mathrm{m}$ (Fig. 5C). These all occurred within the rostral-most $30 \%$ of the nucleus, but labeling extended to nearly the caudal end of VTA. A Friedman test comparing the distance to the median sections for the various populations was found to be nonsignificant $\left[X^{2}(2, n=9)=2.000, p=0.368\right]$.

\subsection{Dorsal raphe nucleus}

Representative low and high power images of retrogradely labeled DRN cells are shown in Fig. 6. Eight hundred and twenty retrogradely labeled cells were identified in DRN across nine animals. Two hundred and sixty eight cells were found to project to OFC, 350 cells projected to the $\mathrm{mPFC}$, and 160 cells projected to ACC. Fourteen cells collateralized to both OFC and mPFC, 7 cells collateralized to OFC and ACC, and 17 cells collateralized to $\mathrm{mPFC}$ and ACC. Four cells possessed axon collaterals targeting all three regions simultaneously (Fig. 7B). A chi square goodness of fit test was performed to determine if populations within the nucleus differed in size and was found to be highly significant $\left[X^{2}(6, n=820)=\right.$ $1059.363, p=0.000]$. 
The rostrocaudal distribution of retrogradely labeled cells in the DRN (Fig. 7A) showed that cells tended to cluster in the central portion of the dorsomedial zone of the DRN, dorsal to the medial longitudinal fasciculus. The average distance \pm -SEM between the most rostral point of DRN (-7.04 mm AP from bregma) and the median section for each population of projection cells were as follows: OFC: $940.00 \pm 58.31 \mu \mathrm{m}$; mPFC: $1160 \pm 67.82 \mu \mathrm{m}$; ACC: $1080.00 \pm 42.42 \mu \mathrm{m}$ (Fig. 7C). These all occurred within the rostral half of the nucleus, and the populations extended roughly $66 \%$ of its length. A Friedman test comparing the distances to the median sections was found to be statistically significant $\left[X^{2}(2, n=\right.$ $9)=8.867, p=0.012]$. Post-hoc pair-wise Wilcoxon signed rank tests were performed with a sequential Bonferroni correction applied to compare these same values between pairs of projection cell populations. Comparisons between the distance to the median sections of OFC and ACC projection neurons $(\mathrm{Z}=-1.823, \mathrm{p}=0.068)$, and $\mathrm{mPFC}$ and $\mathrm{ACC}$ projection neurons $(\mathrm{Z}=-1.265, p=0.206)$ were found to be nonsignificant. The comparison between populations of $\mathrm{mPFC}$ and $\mathrm{OFC}$ projection neurons, however, was found to be statistically significant $(\mathrm{Z}=-2.598, p=0.009)$.

\subsection{Locus coeruleus}

Representative low and high power images of retrogradely labeled LC cells are shown in Fig. 8. A total of 379 retrogradely labeled LC cells were identified across nine animals. Hundred and nine cells were found to project to OFC, 183 cells projected to mPFC, and 72 cells projected to ACC. Six cells collateralized to both OFC and mPFC, 2 cells projected to $\mathrm{OFC}$ and ACC, and 7 cells projected to $\mathrm{mPFC}$ and ACC. No cells were found that projected to all three regions simultaneously (Fig. 9B). A chi square goodness of fit test was performed to determine if populations within the nucleus differed in size and was found to be highly significant $\left.\left(X^{2}(6), n=379\right)=422.736, p=0.000\right)$.

The rostrocaudal distribution of retrogradely labeled cells in the LC (Fig. 9A) shows that retrogradely labeled cells tended to fill the compact core of the nucleus without any other evidence of topographic ordering. The average distance \pm SEM between the most rostral point of LC ( $-9.16 \mathrm{~mm}$ AP from bregma) and the median section for each population of projection cells was as follows: OFC: $500.00 \pm 65.57 \mu \mathrm{m}$; mPFC: $600.00 \pm 30.00 \mu \mathrm{m}$; ACC: $540.00 \pm 42.42 \mu \mathrm{m}$ (Fig. 9C). The median sections all fell within the rostral half of the nucleus, and the populations extended roughly $75 \%$ of its length. A Friedman test comparing the distances to the median section for each population was found to be nonsignificant $\left[X^{2}(2, n=9)=2.000, p=0.368\right]$.

\subsection{Internudear differences}

To determine if differences existed between nuclei in the tendency for their PFC projection neurons to cluster along their rostrocaudal axes, topography ratios were calculated for each animal (Fig. 10). For the two animals from which NB data was missing, the mode was substituted as the numerator of the ratio. A value of 0.00 for this ratio would indicate that all retrogradely labeled cells were located in the most rostral section of the nuclei, 1.00 would indicate that all were located in the most caudal section of the nuclei, and a value of 0.50 would indicate that half of all cells were rostral, and the other half caudal, to the central section of the nucleus. A Friedman's test with significance level set to 0.05 was found to be highly significant $\left[X^{2}(3, n=9)=23.133, p=0.000\right]$. Post-hoc pair-wise Wilcoxon signed rank tests were performed with a sequential Bonferroni correction applied. The comparisons between VTA and NB $(\mathrm{Z}=-2.719, \mathrm{p}=0.007)$, DRN and NB $(\mathrm{Z}=-2.677, p=0.007), \mathrm{LC}$ and NB $(Z=-2.701, p=0.007)$, DRN and VTA $(Z=-2.558, p=0.011)$, and LC and VTA ( $Z$ $=-2.687, p=0.007)$ were all found to be significant. The comparison between and DRN and LC ( $\mathrm{Z}=-0.892, p=0.373)$ was not found to be nonsignificant. 
To determine if the relative sizes of populations of single-and multi-labeled cells were consistent between nuclei a chi square contingency test was performed and found to be highly significant $\left[X^{2}(3, n=9)=954.838, p=0.000\right]$. Post-hoc pair-wise comparisons were performed with A Bonferroni correction applied such that significance was set to $\mathrm{p}=0.0083$. The comparison between DRN and LC was found to be nonsignificant $\left[X^{2}(1, n=9)=0.776\right.$, $p=0.378$. The comparisons between VTA and NB $\left[X^{2}(1, n=9)=553.276, p=0.000\right]$, VTA and DRN $\left[X^{2}(1, n=9)=28.737, p=0.000\right]$, VTA and LC $\left[X^{2}(1, n=9)=20.902, p=\right.$ $0.000], \mathrm{NB}$ and DRN $\left[X^{2}(1, n=9)=537.476, p=0.000\right]$, and NB and LC $\left[X^{2}(1, n=9)=\right.$ $321.416, p=0.000$ ] were all found to be highly significant (data not shown).

\section{Discussion}

This study is the first of its kind to actively compare the distribution and collateralization of projections arising from the major brainstem neuromodulatory systems and terminating in subregions of the PFC. We used multiple, counterbalanced fluorescent retrograde tracer injections in single animals to identify and compare the distributions and relative size of the populations of neurons comprising these projection systems. We further characterized the degree of axonal collateralization among neurons that project to PFC subregions. Our results demonstrate that VTA, DRN and LC projection neurons targeting PFC are largely nondivergent and possess restricted axons typically targeting only one of three subregions. The PFC projection originating in NB, on the other hand, is comprised of both divergent and non-divergent neurons.

\subsection{Technical considerations}

As with any retrograde tracing experiment designed to assess axon collateral projections to distributed terminal fields, one must carefully consider the properties of each tracer employed. Many tracers are available, including fluorescently labeled latex microspheres, Fluoro Gold, Fast Blue, nuclear yellow, and several dextran conjugates of varying molecular weight. In this study, we used rhodamine, fluorescein, and Cascade Blue tagged 10,000 Da dextran solutions as our retrograde tracers of choice to ensure that all were as structurally similar as possible, thereby increasing the likelihood of uniform uptake and transport in all terminal fields. This was necessary because all animals received three different tracer injections, one into each PFC subregion. These high molecular weight dextrans have been well validated for use in retrograde tract tracing studies (Schofield, 2008; Schofield et al., 2007). However, if it was in fact the case that one of the tracers was more efficiently taken up and transported than others, injections were counterbalanced between subjects to correct for any disproportions in the data. It has been shown previously that a combined injection of fluorescein and rhodamine 10,000 Da dextran into the same structure produces $>96 \%$ double labeling of afferent neurons (Schofield et al., 2007); as such, these tracers are clearly capable of producing substantial retrograde double labeling. Although higher molecular weight dextrans are typically used for anterograde tracing, we have likewise shown that these tracers also show strong propensity for retrograde transport. Importantly, we obtained similar results for the $\mathrm{LC}$ projection to $\mathrm{OFC}$ and $\mathrm{mPFC}$ using more conventional retrograde tracer substances (red and green fluorescently labeled latex microspheres, LumaFluor, Naples FL, see Fig. S1). In the present study we included the ACC as a region of interest. Thus, it was necessary to use an additional tracer; as such, we selected fluorescent dextrans which are available with a variety of fluorescent markers. Because our unpublished data (Fig. S1) using latex microspheres so closely match the present data, we believe that the results obtained for VTA, DRN and LC accurately reflect the absence of divergent axons projecting to OFC, mPFC and ACC, and not an artifact of preferential or competitive tracer uptake and transport. This is further supported by the data obtained for NB, which shows 
large populations of divergent axons within the same animals, suggesting that uptake of multiple tracers can occur in multiple axons originating from the same cell.

A potential explanation for the lack of divergence of DRN and LC neurons identified here lies in the choice of tracer. Many previous retrograde tract tracing studies investigating the projection from these nuclei to various brain structures employed the use of low molecular weight tracers (Del Cid-Pellitero and Garzon, 2011; Fallon and Loughlin, 1982; Kirifides et al., 2001; Loughlin and Fallon, 1984; Loughlin et al., 1982; Lu et al., 2001; O'Hearn and Molliver, 1984; Simpson et al., 1997; Van Bockstaele et al., 1993; Villar et al., 1988; Wilson and Molliver, 1991). Recent physiological and ultrastructural studies, however, suggest that cells within these nuclei may in fact be electrotonically coupled via gap junctions (Alvarez-Maubecin et al., 2000; Ballantyne et al., 2004; Buma et al., 1992; Fuxe et al., 2007; Ishimatsu and Williams, 1996; Masaki et al., 2004; Oyamada et al., 1999; Rash et al., 2007; Van Bockstaele et al., 2004; Yasui et al., 2007). While not all gap junctions are composed of the same connexin subunits (Nicholson et al., 2000; Weber et al., 2004), it is generally accepted that they allow the diffusion of molecules up to 1000 Da directly between cells (Harris, 2001; Weber et al., 2004; Yeager and Nicholson, 1996). The molecular weights of Fluoro-gold, propridium iodide, nuclear yellow, fast blue, and true blue are 532.6, 668.4, 651.01, 300.35, and 578.87 Da, respectively. Therefore, prior accounts of multiple labeled, highly divergent neurons in DRN and LC projecting to functionally distinct and spatially segregated brain regions may have been an artifact of low molecular weight tracers diffusing into neurons which, in reality, do not project to multiple diverse targets. Future experiments may revisit this issue with higher molecular weight tracers such as the 10,000 Da fluorescent dextrans we have used here. Such studies could potentially alter the current understanding of the anatomy of these ascending modulatory systems. High molecular weight tracers were intentionally chosen in this study rather than $3000 \mathrm{Da}$ or smaller dextrans to eliminate any possibility of diffusion between gap junctions. These 10,000 Da dextrans have previously been shown to produce effective retrograde transport in brain (Schofield, 2008; Schofield et al., 2007; Vercelli et al., 2000), which is in agreement with the high number of retrogradely labeled somata we have shown in this study.

It is equally important to assess the degree of variability between injections within and between animals when interpreting comparative retrograde tracing data. To identify potential differences between injections into different PFC subregions within and across subjects, the residual fluorescence from representative injection site sections were mapped onto corresponding atlas images. The areas of each of the regions containing this residual fluorescence were calculated using ImageJ software (NIH). These values were multiplied by the distance between consecutive representative sections $(0.5 \mathrm{~mm})$, and summed to produce a representative index of the volume of tissue in each cortical region that was exposed to tracer. These values were compared using a mixed design ANOVA. This analysis showed that a significantly greater volume of OFC was exposed to tracer than $\mathrm{mPFC}$. This may indicate that the number of identified OFC projection neurons throughout the brain may be disproportionately large compared to the other populations of retrogradely labeled projection cells. It is also important to note that in some animals, tracers sometimes diffused farther rostrally and caudally than in others. Therefore, subsets of projection cells could potentially be identified in these brains that could not be revealed in others. For example, if we were to subdivide OFC into rostral, intermediate, and caudal zones, and these zones were innervated by discreet populations of afferent cells, then differential proportions of these populations would be labeled in different animals depending on how far the tracer diffused from the intermediate region into the rostral and caudal regions, case by case. However, our data are pooled from across all animals to provide a more global perspective of the innervation patterns of OFC, mPFC and ACC as singular entities, rather than further subdividing them. 
Future studies may investigate whether such differences in afferent projection patterns exist between subregions of OFC, mPFC and ACC. Such fine grained anatomical resolution could not be achieved in the present study. However, despite the difference in the volume of OFC and $\mathrm{mPFC}$ filled by tracer injection, and the inter-animal variability between the boundaries of affected tissues, the main finding of non-divergent projections of VTA, DRN and LC neurons, and more pronounced collateralization of NB neurons to PFC subregions, remains the same. These anatomical findings and their functional implications for each nucleus and for these systems in general are considered below.

\subsection{Nucleus basdlis}

Through the use of multiple fluorescent retrograde tracers, NB was determined to contain a large proportion of neurons projecting to multiple PFC terminal field regions simultaneously. This is in direct contrast to previous accounts of cholinergic NB anatomy which have described mostly single-labeled non-divergent neurons following injection of multiple retrograde tracers into various forebrain regions (Bigl et al., 1982; Carlsen et al., 1985; Coyle et al., 1983; McKinney et al., 1983; Price and Stern, 1983). These prior studies, however, tended to inject pairs of structures that were either functionally unrelated or spatially distant from one another. The present study concentrated on PFC sub-regions associated with specific aspects of cognitive function. Because of the axon collateral distribution from individual cells our results suggest that global PFC function may be optimized by uniform and synchronous acetylcholine release throughout its subregions. It has been shown that acetylcholine release in neocortex generally promotes vigilance and environmental awareness by desynchronizing slow cortical EEG patterns, and also increases the signal to noise ratio of incoming sensory information (Wenk, 1997). Furthermore, acetylcholine acts on both GABAergic and glutamatergic systems in cortex to suppress weaker inputs more than strong inputs (Metherate and Ashe, 1995a, 1995b; Metherate et al., 1992), which may prepare discrete PFC networks to respond to specific behaviorally relevant stimuli that elicit large neural responses, while filtering out behaviorally irrelevant stimuli that do not. The efferent topography that we have identified here is in general agreement with previous accounts of NB anatomy (McKinney et al., 1983; Pang et al., 1993), although no unique topographical organizations for individual populations of projection systems were identified.

\subsection{Ventral tegmental area}

While this portion of the study was primarily designed to identify the dopaminergic projection to subregions of PFC, we unexpectedly found a high proportion of non-TH immunoreactive retrogradely labeled neurons (Fig. 4). Note that only one cell in Fig. 4 (column i, upper left, mPFC projection neuron) was tyrosine hydroxylase (TH) positive. This indicates the existence of a major non-dopaminergic pathway arising in VTA and terminating in OFC, mPFC and ACC. Because we did not quantify the proportion of cells within these populations that were TH versus non-TH immunoreactive, future studies should focus on identifying these neurochemical subtypes and clarifying the uniqueness of their relationship to PFC projection targets. However, our findings of mostly non-divergent VTA neurons targeting OFC, $\mathrm{mPFC}$ and $\mathrm{ACC}$ are consistent with prior accounts of its anatomy (Loughlin and Fallon, 1984; Sobel and Corbett, 1984). The rostrocaudal distribution of retrogradely labeled VTA neurons we have identified is also in general agreement with literature reports of its efferent topography (Beckstead et al., 1979; Carter and Fibiger, 1977; Fallon et al., 1978; Fallon and Loughlin, 1982; Fallon and Moore, 1978a, 1978b; Loughlin and Fallon, 1984; Sobel and Corbett, 1984), although the efferent topographies observed did not differ from one population of projection neurons to the next. The organization reported here suggests that dopamine or other transmitter release may occur independently in OFC, $\mathrm{mPFC}$ and ACC. Furthermore, the disparate size of these independent projections suggests 
that transmitter release is not uniform across all three subregions. OFC receives input from the greatest number of cells in VTA, and therefore may be subject to the greatest degree of regulation via VTA output. However, this is also dependent on several other factors, including the density of release points in each of the terminal fields, as well as the distribution of receptors, transporters, and metabolic enzymes expressed in the target tissue. Future studies will be needed to explore this possibility.

\subsection{Dorsal raphe nucleus}

In DRN we identified independent populations of non-collateralizing DRN neurons projecting to OFC, mPFC and ACC. This contradicts previous accounts of DRN anatomy, which have shown the nucleus to be more divergent than VTA. However, the lack of overlap between cells projecting to subregions of PFC does agree with previous observations that single axons collateralize to innervate functionally related structures (Abrams et al., 2004; Sobel and Corbett, 1984; Van Bockstaele et al., 1993). Furthermore, our findings are also in general agreement with prior reports of the efferent topography of the nucleus (Abrams et al., 2004; Kirifides et al., 2001; O'Hearn and Molliver, 1984; Van Bockstaele et al., 1993; Vertes, 1991; Villar et al., 1988; Waterhouse et al., 1986, 1993) such that the majority of retrogradely labeled cells were found in the rostral and central portions of the nucleus, just dorsal to the medial longitudinal fasiculus. No cells were identified in the lateral wings, which are typically viewed as sub-cortically projecting regions of DRN. Interestingly, it was shown that the OFC projection neurons in DRN tend to cluster significantly more rostrally in the nucleus than do those projecting to $\mathrm{mPFC}$. This anatomical segregation may underscore other potential differences between these groups of cells, such as neurochemical or physiological disparities. This possibility remains to be explored. However, as was the case in VTA, it appears that the DRN maintains an efferent topographic organization capable of independent serotonin release in PFC subregions. Likewise, the size of these projections was not uniform, such that injection of tracer into mPFC consistently labeled the most DRN cells. Again, this anatomical feature may provide for differential release of serotonin in OFC, mPFC and ACC, thereby promoting distinct network effects between regions upon global activation of DRN. Physiological analyses of the serotonergic system in subregions of PFC are needed to validate these hypotheses. As in VTA, the neurochemistry of retrogradely labeled cells was not consistent: both serotonin immunoreactive and nonserotonergic neurons were identified in DRN that projected to the various subregions of PFC. Future studies should further explore the relationship between these neurochemical phenotypes and prefrontal projection targets.

\subsection{Locus coeruleus}

Previous reports of LC anatomy agree that all neurons within the borders of the nucleus contain norepinephrine and thus we conclude that all of the prefrontal projection neurons observed here were noradrenergic. The results of many studies indicate that this nucleus is highly divergent with modest efferent topography (Fallon and Loughlin, 1982; Loughlin et al., 1982; Waterhouse et al., 1983,1993). While our data likewise support a lack of stringent efferent topography, they strongly contrast with accounts of its axonal divergence.

Accordingly, LC is anatomically structured to promote independent norepinephrine release in, and modulation of, OFC, mPFC and ACC. Under appropriate conditions independent activation of subsets of LC-PFC projection neurons would therefore provide for discrete release of norepinephrine in PFC subregions. The distribution of efferent neurons identified in LC was similar to that identified in DRN, such that the largest population of labeled cells projected to mPFC. Thus, the same potential physiological principles may apply to DRN and LC such that with simultaneous or near simultaneous activation of the nucleus, norepinephrine would still be differentially distributed across PFC subregions. Although LC containing sections underwent immunofluorescent staining for galanin rather than $\mathrm{TH}$ or 
dopamine p hydroxylase (DBH), this procedure still allowed us to identify the boundaries of the nucleus. This was done to permit us to identify neurochemical heterogeneity amongst LC-PFC projection cells, as it is known that all cells within this nucleus express DBH and therefore contain norepinephrine (Berridge and Waterhouse, 2003). It is important to note that some, but not all retrogradely labeled cells in LC expressed the neuropeptide galanin. This suggests that this neuroactive peptide may be released from some but not all terminals in PFC. An important consideration for future studies is the relative distribution of galanincontaining projections to PFC subregions, as this may result in differential release and therefore unique peptidergic effects on terminal field physiology.

The organization of the LC efferent projection identified here accords well with adaptive gain theory, a computational model of LC function (Aston-Jones and Cohen, 2005a, 2005b). This model suggests that during optimal behavioral performance, LC neurons are capable of acting as independent units and modulating restricted terminal field regions to promote exploitation of the current behavioral strategy. Then, as behavioral performance decreases, or in times of stress, LC neurons begin to fire tonically en masse through dendritic electrotonic coupling, orchestrating a more homogeneous effect on network properties throughout all terminal field regions of LC (Aston-Jones and Cohen, 2005a, 2005b). In this mode, animals are less focused on specific stimuli, and scan the external world in order to identify new relevant stimuli or escape strategies from environmental threats. At this point, LC neurons begin to fire phasically and independently again to promote a newly adaptive behavioral strategy. The distribution of LC efferents that we have demonstrated fits well with this theory, i.e., independent modulation of prefrontal subregions to promote dissociable behavioral operations of these areas would depend on the existence of neuronal subpopulations that project exclusively to restricted targets. Then, as the utility of a behavioral strategy declines, these LC-PFC projection neurons begin to fire together, affecting the network properties of all subregions simultaneously, and changing the behavioral output of the animal. The distribution of LC efferents may, therefore, be highly relevant with regard to the maintenance of executive functions.

\subsection{Internudear differences}

In addition to the differences in size of the populations of cells projecting to OFC, $\mathrm{mPFC}$ and ACC within nuclei, we have also shown that the levels of axonal divergence are not consistent between nuclei. Specifically, NB contained a significantly greater proportion of multi-labeled neurons than did VTA, DRN and LC, while VTA contained a significantly greater proportion of multi-labeled neurons than did DRN or LC. The latter two nuclei, on the other hand, shared similar proportions of single and multi labeled neurons projecting to the various subregions of PFC. These data suggest that the degree of axonal collateralization to subregions of PFC is not uniform between all ascending neuromodulatory systems. We also showed that cumulative populations of all PFC projection neurons are not equally distributed along the rostrocaudal extents between nuclei. Specifically, projection cells were clustered significantly more rostrally in NB than they were in VTA, DRN and LC, while those in VTA were clustered significantly more rostrally than those in DRN and LC. LC and DRN, on the other hand, showed similar rostrocaudal distributions of PFC projection neurons (Fig. 10). Taken together, these distribution patterns may indicate the anatomical segregation of prefrontal function within these nuclei.

\section{Conclusions}

Based on their anatomical properties, neurons in VTA, DRN and LC appear to be anatomically aligned to promote independent modulation of OFC, mPFC and ACC. This may suggest the existence of a previously unidentified segregation of prefrontal cortical function within these nuclei. Whether or not these nuclei are physiologically capable of such 
independent modulatory actions, and the consequence of such an organization on prefrontal network properties however, remains to be explored. Conversely, NB was found to be highly divergent, with many cells possessing axons targeting two or more prefrontal subregions simultaneously. Therefore, activation of these cells results in a more uniform release of acetylcholine across several terminal fields simultaneously. This, however, does not suggest that this organization is random and indiscriminant; it may rather indicate that prefrontal function is optimized by widespread acetylcholine release. Furthermore, these results show that cells within NB, VTA, DRN and LC do not project to each prefrontal terminal field, or combination thereof, with equal probability. This suggests that these organizations are not reflective of some underlying developmental processes that randomly bring axons from these cells to subregions of PFC. Rather, these nuclear organizations appear to be developmentally programmed and may have some functional bearing on prefrontal cortical pharmacology and physiology.

The observations in this study are strictly anatomical in nature, and thus, we are unable to definitively state with any degree of certainty their physiologic consequence. A multifaceted approach that attempts to characterize these populations of cells through biochemical, pharmacological and physiological assays will provide a multi-level analysis of their biology and provide novel insights to their regulatory role in PFC-dependent behavior, cognition and executive function. Such studies could potentially reveal a previously unrecognized segregation of prefrontal cortical function in these four ascending neuromodulatory nuclei and provide a means of independently or globally regulating their prefrontal terminal fields for both experimental and therapeutic purposes. Furthermore, the efferent topographies and distributions identified in this study represent the state of the healthy adult ascending neuromodulatory pathways. A goal of future studies is to compare the distribution of prefrontal projection neurons within these nuclei in animal models of neuropsychiatric and neurodegenerative disease. For example, evidence suggests that in Alzheimer's and Parksinson's diseases, some LC neurons degenerate selectively (Gesi et al., 2000; Grimm et al., 2004; McMillan et al., 2011; Miguelez et al., 2011; Szot et al., 2010; Weinshenker, 2008). It may be that such degeneration targets LC-PFC projection neurons that play a role in the cognitive decline associated with these diseases. The current findings provide a rationale for additional experiments designed to further characterize basal forebrain and brainstem PFC projection neurons on the basis of different physiological properties, as well as determine the susceptibility of these organizations to pharmacological, biochemical, environmental, pathological or genetic insult. Such studies would be instrumental in furthering the collective understanding of the roles of these ascending neuromodulatory systems in normal PFC and cognitive function, as well as their dysfunction and contribution various pathophysiological processes.

\section{Experimental procedures}

\subsection{Retrograde tracing}

The Drexel University College of Medicine Institutional Animal Care and Use Committee (IACUC) approved all animal procedures and protocols. Ten young adult male SpragueDawley rats (Taconic), weighing between 250 and $350 \mathrm{~g}$ were used in this study. Each rat was deeply anesthetized through isoflurane inhalation (4\%) and placed in a stereotaxic frame. Isoflurane concentration was decreased to $2.5 \%$ after reaching a surgical plane of anesthesia. Body temperatures were monitored and controlled throughout the entire surgical procedure. Coordinates for tracer injection (Paxinos and Watson, 1997) from bregma, were as follows: $\mathrm{OFC}: \mathrm{AP}=+4.2 \mathrm{~mm} ; \mathrm{ML}= \pm 3.0 \mathrm{~mm} ; \mathrm{DV}=-3.2 \mathrm{~mm} @ 15^{\circ}$ from the dura; mPFC: $\mathrm{AP}= \pm 3.2 \mathrm{~mm} ; \mathrm{ML}= \pm 1.8 \mathrm{~mm}, \mathrm{DV}=-3.9 \mathrm{~mm} @ 15^{\circ}$ from the dura; $\mathrm{ACC}: \mathrm{AP}=+1.5$ $\mathrm{mm} ; \mathrm{ML}= \pm 1.3 \mathrm{~mm}$; DV $=-2.5 @ 15 \mathrm{deg} \mathrm{mm}$ from the dura. All injections were made into the left hemisphere. Craniotomies were drilled and a 32 gauge steel microinjection cannula 
connected to a $1.0 \mu \mathrm{l}$ Hamilton syringe via polyethylene tubing was stereotaxically lowered to each DV coordinate, and withdrawn by $0.2 \mathrm{~mm}$. A $0.3 \mu \mathrm{l}$ injection of one of three fluorescently labeled 10,000 Da dextran solutions (2\% in 0.1 M PBS; Fluoro Ruby, Fluoro Emerald, and Cascade Blue dextran, Invitrogen) was made independently into each region using a motorized syringe pump (World Precision Instruments SP101I), into each region at a flow rate of $0.036 \mu \mathrm{l} / \mathrm{min}$. Each cannula remained in place for $20 \mathrm{~min}$ before removal. Injections were counterbalanced between surgeries. Craniotomies were filled with sterile bone wax, and the incision was closed with wound clips. Following a survival time of 7 days, the rats were deeply anesthetized with $4 \%$ isoflurane and perfused through the heart with $300 \mathrm{ml} 0.1 \mathrm{M}$ phosphate buffer followed by $500 \mathrm{ml} 4 \%$ paraformaldehyde (PFA) solution. The rats were decapitated and their brains were extracted. The brains were postfixed overnight in 4\% PFA solution, and cryoprotected in $20 \%$ sucrose solution.

\subsection{Tissue processing and immunofluorescence}

On a Leica sliding freezing microtome, $80 \mu \mathrm{m}$ coronal sections of prefrontal cortex were collected in PBS, mounted on gelatin coated slides, counterstained with deep red fluorescent Nissl stain (Invitrogen) and cover slipped with FluoroMount (Sigma) for verification of injection sites. Next, a 1:6 series of $30 \mu \mathrm{m}$ coronal sections containing the nuclei of interest were collected in $0.1 \mathrm{M}$ phosphate buffered saline (PBS); therefore consecutive sections from the same series were $180 \mu \mathrm{m}$ apart. Sections underwent immunofluorescent processing to define neurochemically specific boundaries of each nucleus. For all stains, sections underwent three $10 \mathrm{~min}$ washes is $0.1 \mathrm{M}$ PBS, followed by a 90 min preincubation in $4 \%$ normal serum in $0.1 \mathrm{M}$ phosphate buffered saline containing $0.3 \%$ Triton-X (PBST) and were then transferred to a primary antiserum solutions (1:500 in PBST). Sections were incubated in the antiserum for $48 \mathrm{~h}$ at $4^{\circ}$ before undergoing three 10 min washes in $0.1 \mathrm{M}$ PBS. Sections were then incubated in secondary antiserum solutions (1:500 in PBST). After three final 10 min washes in $0.1 \mathrm{M}$ PBS, sections were mounted on gelatin-coated glass slides, air-dried, cleared in xylene for $1 \mathrm{~min}$, air dried a second time and cover-slipped with FluoroMount (Sigma). Sections were immunostained using the following antibodies:

$N B$ : primary: goat anti-vesicular acetylcholine transporter (VAChT; ImmunoStar 24286; 1:500); secondary: rabbit anti-goat AlexaFluor 647 (Invitrogen, 1:500). Immunolabeling is completely abolished by pre-adsorption with synthetic rat peptide corresponding to VAChT amino acids 511-530, and the antibody recognizes recombinant VAChT but not vesicular monoamine transporter in transfected cells (Arvidsson et al., 1997). Immunolabeling is also completely abolished by the exclusion of the antibody from the primary antiserum.

VTA: primary: rabbit anti-tyrosine hydroxylase (TH; Milli-pore AB152; 1:500); secondary: goat anti-rabbit AlexaFluor 647 (Invitrogen 1:500). The anti-TH antibody recognizes a band of $62 \mathrm{kDa}$ by Western blot (manufacturer data sheet). TH staining was abolished by the exclusion of the antibody from the primary antiserum.

$D R N$ : primary: rabbit anti-5HT (Sigma S5545; 1:500); secondary: goat anti-rabbit AlexaFluor 647 (Invitrogen, 1:500). Immunostaining is abolished by preincubation of diluted antiserum with $500 \mu \mathrm{M}$ serotonin or $200 \mu g / \mathrm{ml}$ BSA-conjugated serotonin. Staining is not inhibited by preincubation with $500 \mu \mathrm{M}$ L-tryptophan, 5-hydroxytryptophan, $\mathrm{N}$ acetylserotonin or dopamine (manufacturer data sheet). Exclusion of the antibody from the primary antiserum completely abolishes immunolabeling.

LC. primary: rabbit anti-galanin (Peninsula Labs T4334; 1:500), secondary: goat anti-rabbit AlexaFluor 647 (Invitrogen, 1:500). The primary antibody interacts with rat, human and porcine galanin, but not vasoactive intestinal peptide, secretin, substance $\mathrm{P}$, or neuropeptide $\mathrm{Y}$ (manufacturer data sheet), and recognizes a single $13 \mathrm{kDa}$ band on a Western blot 
(UniProt, 2009). Preincubation of the primary antiserum with the immunizing peptide abolishes all immunostaining (Landry et al., 2006). Immunostaining was also abolished by the exclusion of the anti-galanin antibody from the primary antiserum.

\subsection{Verification of injection sites}

A Leica DMR fluorescence microscope equipped with a Qlmaging Retiga EXi Camera (Model RGB-MS-C) was used to photograph the residual fluorescent "halo" produced by tracer injection in PFC sections $0.5 \mathrm{~mm}$ apart. These images were then mapped onto corresponding atlas images (Paxinos and Watson, 1997), and the areas of the portions of tissue containing fluorescence were calculated using ImageJ software (NIH) for every section. To obtain an estimated volume of OFC, mPFC and ACC that was filled by tracer in each animal, these areas were summed for each PFC subregion, and then the values were multiplied by the distance between representative sections $(0.5 \mathrm{~mm})$. These values were compared using a mixed design ANOVA.

\subsection{Cell counting}

A Leica DMR fluorescence microscope equipped with a Qlmaging Retiga EXi Camera (Model RGB-MS-C) was used to verify injection sites and visualize NB, VTA, DRN and LC. Any brains in which tracer was found to have diffused beyond anatomically defined borders of OFC, mPFC or ACC were excluded from subsequent analysis $(n=1)$. Nuclei were visually scanned at $40 \times$ magnification through all three fluorescence filters to identify potential retrogradely labeled neurons. Whenever a cell was identified, it was surveyed through all four fluorescence channels at $63 \times$ magnification to confirm which tracers it contained and its neurochemical identity. Injection site images $(1.0 \times)$, as well as low $(10 \times$ $-20 \times$ ) and high power $(100 \times)$ fluorescent photomicrographs containing source nuclei were generated with QCapture Pro software. Because of the diffuse nature of the cholinergic cells in NB, only retrogradely labeled cells that stained positively for VAChT were included in the analysis. VTA, DRN and LC, on the other hand, are more compact, and well defined anatomical boundaries of these nuclei were evident from visual inspection and on the basis of TH, 5HT and galanin immunofluorescence, respectively. Any retrogradely labeled cells within these neurochemically defined anatomical boundaries of the nuclei were included in the analysis, including those that did not stain positively for TH, 5HT, and galanin.

\subsection{Analysis}

For each nucleus, a chi square goodness of fit test was performed to test the null hypothesis that cells project to each possible combination of terminal fields (OFC only, mPFC only, ACC only, OFC and mPFC, OFC and ACC, mPFC and ACC, OFC, mPFC and ACC) with equal probability (expected value for each population=total number of retrogradely labeled cells/7). Significance level was set to $p=0.05$.

To determine if unique intranuclear topographies existed for any of these populations, for each nucleus in each animal, the distance between the most rostral brain section containing each nucleus and the section in which half of all the retrogradely labeled cells were rostral and the other half caudal (the median section), was calculated. These values were then compared with a Friedman test with significance set to $p=0.05$. For nuclei in which significance was revealed by the Friedman test, individual pair-wise post-hoc Wilcoxon signed rank tests were performed, with a sequential Bonferroni correction applied.

To determine if the level of axonal divergence was consistent between nuclei, a 4 (nucleus) $\times 2$ (labeling; single or multi-labeled) chi square contingency test was performed with significance level set to $\mathrm{p}=0.05$. Post-hoc pair-wise comparisons were made with individual $2 \times 2$ chi square contingency tests with a sequential Bonferroni correction applied. 
To determine whether or not there were differences in the rostrocaudal clustering of retrogradely labeled cells between nuclei, the position of the median section of all retrogradely labeled cells in each nucleus of each animal was determined. A ratio of this number relative to the absolute length of each nucleus as determined by Paxinos and Watson (1997) was created (hereafter referred to as the topography ratio), and these numbers were compared by a Friedman test with significance level set to $p=0.05$.

\section{Supplementary Material}

Refer to Web version on PubMed Central for supplementary material.

\section{Acknowledgments}

We would like to acknowledge Dr. Brian Clark for his assistance in the statistical analysis of data, and Miss Ashley Smith for her technical assistance.

Funding

This work is supported by National Institutes on Drug Abuse (DA017960) and National Institutes of Mental Health (MH087921) and an award from the Drexel University Human Cognition Enhancement Program.

\section{Abbreviations}

$\begin{array}{ll}\text { OFC } & \text { Orbitofrontal cortex } \\ \text { mPFC } & \text { medial prefrontal cortex } \\ \text { ACC } & \text { anterior cingulate cortex } \\ \text { NB } & \text { nucleus basalis } \\ \text { VTA } & \text { ventral tegmental area } \\ \text { DRN } & \text { dorsal raphe nucleus } \\ \text { LC } & \text { locus coeruleus } \\ \text { VAChT } & \text { vesicular acetylcholine transporter } \\ \text { TH } & \text { tyrosine hydroxylase } \\ \text { 5HT } & \text { serotonin }\end{array}$

\section{REFERENCES}

Abrams JK, Johnson PL, Hollis JH, Lowry CA. Anatomic and functional topography of the dorsal raphe nucleus. Ann. N. Y. Acad. Sci. 2004; 1018:46-57. [PubMed: 15240351]

Alvarez-Maubecin V, Garcia-Hernandez F, Williams JT, Van Bockstaele EJ. Functional coupling between neurons and glia. J. Neurosci. 2000; 20(11):4091-4098. [PubMed: 10818144]

Arvidsson U, Riedl M, Elde R, Meister B. Vesicular acetylcholine transporter (VAChT) protein: a novel and unique marker for cholinergic neurons in the central and peripheral nervous systems. J. Comp. Neurol. 1997; 378(4):454-167. [PubMed: 9034903]

Aston-Jones G, Cohen JD. Adaptive gain and the role of the locus coeruleus-norepinephrine system in optimal performance. J. Comp. Neurol. 2005a; 493(1):99-110. [PubMed: 16254995]

Aston-Jones G, Cohen JD. An integrative theory of locus coeruleus-norepinephrine function: adaptive gain and optimal performance. Annu. Rev. Neurosci. 2005b; 28:403-450. [PubMed: 16022602]

Ballantyne D, Andrzejewski M, Muckenhoff K, Scheid P. Rhythms, synchrony and electrical coupling in the Locus coeruleus. Respir. Physiol. Neurobiol. 2004; 143(2-3):199-214. [PubMed: 15519556] 
Beckstead RM, Domesick VB, Nauta WJ. Efferent connections of the substantia nigra and ventral tegmental area in the rat. Brain Res. 1979; 175(2):191-217. [PubMed: 314832]

Berridge CW, Waterhouse BD. The locus coeruleus-noradrenergic system: modulation of behavioral state and state-dependent cognitive processes. Brain Res. Brain Res. Rev. 2003; 42(1):33-84. [PubMed: 12668290]

Bigl V, Woolf NJ, Butcher LL. Cholinergic projections from the basal forebrain to frontal, parietal, temporal, occipital, and cingulate cortices: a combined fluorescent tracer and acetylcholinesterase analysis. Brain Res. Bull. 1982; 8(6):727-749. [PubMed: 6182962]

Brown VJ, Bowman EM. Rodent models of prefrontal cortical function. Trends Neurosci. 2002; 25(7): 340-343. [PubMed: 12079756]

Buma P, Veening J, Hafmans T, Joosten H, Nieuwenhuys R. Ultrastructure of the periaqueductal graymatter of the rat - an electron-microscopic and horseradish-peroxidase study. J. Comp. Neurol. 1992; 319(4):519-535. [PubMed: 1619043]

Bussey TJ, Everitt BJ, Robbins TW. Dissociable effects of cingulate and medial frontal cortex lesions on stimulus-reward learning using a novel Pavlovian autoshaping procedure for the rat: implications for the neurobiology of emotion. Behav. Neurosci. 1997; 111(5):908-919. [PubMed: 9383513]

Cain RE, Wasserman MC, Waterhouse BD, McGaughy JA. Atomoxetine facilitates attentional set shifting in adolescent rats. Dev. Cogn. Neurosci. 2011; 1(4):552-559. [PubMed: 21927630]

Carlsen J, Zaborszky L, Heimer L. Cholinergic projections from the basal forebrain to the basolateral amygdaloid complex: a combined retrograde fluorescent and immunohistochemical study. J. Comp. Neurol. 1985; 234(2):155-167. [PubMed: 3886715]

Carr DB, ODonnell P, Card JP, Sesack SR. Dopamine terminals in the rat prefrontal cortex synapse on pyramidal cells that project to the nucleus accumbens. J. Neurosci. 1999; 19(24):11049-11060. [PubMed: 10594085]

Carter DA, Fibiger HC. Ascending projections of presumed dopamine-containing neurons in the ventral tegmentum of the rat as demonstrated by horseradish peroxidase. Neuroscience. 1977; 2(4):569-576. [PubMed: 917282]

Chambers RA, Sentir AM, Engleman EA. Ventral and dorsal striatal dopamine efflux and behavior in rats with simple vs. co-morbid histories of cocaine sensitization and neonatal ventral hippocampal lesions. Psychopharmacology (Berlin). 2010; 212(1):73-83. [PubMed: 20631994]

Chandler D, Waterhouse BD. Evidence for broad versus segregated projections from cholinergic and noradrenergic nuclei to functionally and anatomically discrete subregions of prefrontal cortex. Front. Behav. Neurosci. 2012; 6:20. [PubMed: 22661934]

Coyle JT, McKinney M, Johnston MV, Hedreen JC. Synaptic neurochemistry of the basal forebrain cholinergic projection. Psychopharmacol. Bull. 1983; 19(3):441-47. [PubMed: 6635121]

Dalley JW, Cardinal RN, Robbins TW. Prefrontal executive and cognitive functions in rodents: neural and neurochemical substrates. Neurosci. Biobehav. Rev. 2004; 28(7):771-784. [PubMed: 15555683]

Del Cid-Pellitero E, Garzon M. Medial prefrontal cortex receives input from dorsal raphe nucleus neurons targeted by hypocretinl/orexinA-containing axons. Neuroscience. 2011; 172:30-43. [PubMed: 21036204]

Devilbiss DM, Page ME, Waterhouse BD. Locus ceruleus regulates sensory encoding by neurons and networks in waking animals. J. Neurosci. 2006; 26(39):9860-9872. [PubMed: 17005850]

Devilbiss DM, Waterhouse BD. Norepinephrine exhibits two distinct profiles of action on sensory cortical neuron responses to excitatory synaptic stimuli. Synapse. 2000; 37(4):273-282. [PubMed: 10891864]

Devilbiss DM, Waterhouse BD. The effects of tonic locus ceruleus output on sensory-evoked responses of ventral posterior medial thalamic and barrel field cortical neurons in the awake rat. J. Neurosci. 2004; 24(48):10773-10785. [PubMed: 15574728]

Fallon JH, Koziell DA, Moore RY. Catecholamine innervation of the basal forebrain. II. Amygdala, suprarhinal cortex and entorhinal cortex. J. Comp. Neurol. 1978; 180(3):509-532. [PubMed: 659673] 
Fallon JH, Loughlin SE. Monoamine innervation of the forebrain: collateralization. Brain Res. Bull. 1982; 9(1-6):295-307. [PubMed: 6129040]

Fallon JH, Moore RY. Catecholamine innervation of the basal forebrain. III. Olfactory bulb, anterior olfactory nuclei, olfactory tubercle and piriform cortex. J. Comp. Neurol. 1978a; 180(3):533-544. [PubMed: 307009]

Fallon JH, Moore RY. Catecholamine innervation of the basal forebrain IV. Topography of the dopamine projection to the basal forebrain and neostriatum. J. Comp. Neurol. 1978b; 180(3):545580. [PubMed: 659674]

Floresco SB, Block AE, Tse MT. Inactivation of the medial prefrontal cortex of the rat impairs strategy set-shifting, but not reversal learning, using a novel, automated procedure. Behav. Brain Res. 2008; 190(1):85-96. [PubMed: 18359099]

Furuyashiki T, Gallagher M. Neural encoding in the orbitofrontal cortex related to goal-directed behavior. Ann. N. Y. Acad. Sci. 2007; 1121:193-215. [PubMed: 17872389]

Fuster JM. Executive frontal functions. Exp. Brain Res. 2000; 133(1):66-70. [PubMed: 10933211]

Fuxe K, Dahlstrom A, Hoistad M, Marcellino D, Jansson A, Rivera A, Diaz-Cabiale Z, Jacobsen K, Tinner-Staines B, Hagman B, et al. From the Golgi-Cajal mapping to the transmitter-based characterization of the neuronal networks leading to two modes of brain communication: wiring and volume transmission. Brain Res. Rev. 2007; 55(1):17-54. [PubMed: 17433836]

Gesi M, Soldani P, Giorgi FS, Santinami A, Bonaccorsi I, Fomai F. The role of the locus coeruleus in the development of Parkinson's disease. Neurosci. Biobehav. Rev. 2000; 24(6):655-668. [PubMed: 10940440]

Greene JG. Gene expression profiles of brain dopamine neurons and relevance to neuropsychiatric disease. J. Physiol. 2006; 575(Pt 2):411-116. [PubMed: 16740610]

Grimm J, Mueller A, Hefti F, Rosenthal A. Molecular basis for catecholaminergic neuron diversity. Proc. Natl. Acad. Sci. USA. 2004; 101(38):13891-13896. [PubMed: 15353588]

Harris AL. Emerging issues of connexin channels: biophysics fills the gap. Q. Rev. Biophys. 2001; 34(3):325-472. [PubMed: 11838236]

Hoover WB, Vertes RP. Anatomical analysis of afferent projections to the medial prefrontal cortex in the rat. Brain Struct. Funct. 2007; 212(2):149-179. [PubMed: 17717690]

Hurley LM, Devilbiss DM, Waterhouse BD. A matter of focus: monoaminergic modulation of stimulus coding in mammalian sensory networks. Curr. Opin. Neurobiol. 2004; 14(4):488-495. [PubMed: 15321070]

Ishimatsu M, Williams JT. Synchronous activity in locus coeruleus results from dendritic interactions in pericoerulear regions. J. Neurosci. 1996; 16(16):5196-5204. [PubMed: 8756448]

Kirifides ML, Simpson KL, Lin RC, Waterhouse BD. Topographic organization and neurochemical identity of dorsal raphe neurons that project to the trigeminal somatosensory pathway in the rat. J. Comp. Neurol. 2001; 435(3):325-340. [PubMed: 11406815]

Kolb B, Pellis S, Robinson TE. Plasticity and functions of the orbital frontal cortex. Brain Cogn. 2004; 55(1):104-115. [PubMed: 15134846]

Landry M, Bouali-Benazzouz R, Andre C, Shi TJ, Leger C, Nagy F, Hokfelt T. Galanin receptor 1 is expressed in a subpopulation of glutamatergic interneurons in the dorsal horn of the rat spinal cord. J. Comp. Neurol. 2006; 499(3):391-103. [PubMed: 16998907]

Lehmann J, Nagy JI, Atmadia S, Fibiger HC. The nucleus basalis magnocellularis: the origin of a cholinergic projection to the neocortex of the rat. Neuroscience. 1980; 5(7):1161-1174. [PubMed: 7402465]

Li Y, Fang F, Wang X, Lei H. Neuronal projections from ventral tegmental area to forebrain structures in rat studied by manganese-enhanced magnetic resonance imaging. Magn. Reson. Imaging. 2009; 27(3):293-299. [PubMed: 18786796]

Loughlin SE, Fallon JH. Substantia nigra and ventral tegmental area projections to cortex: topography and collateralization. Neuroscience. 1984; 11(2):425-135. [PubMed: 6201780]

Loughlin SE, Foote SL, Fallon JH. Locus coeruleus projections to cortex: topography, morphology and collateralization. Brain Res. Bull. 1982; 9(1-6):287-294. [PubMed: 7172032] 
Lu H, Ozawa H, Nishi M, Ito T, Kawata M. Serotonergic neurones in the dorsal raphe nucleus that project into the medial preoptic area contain oestrogen receptor beta. J. Neuroendocrinol. 2001; 13(10):839-845. [PubMed: 11679052]

Mamounas LA, Molliver ME. Evidence for dual serotonergic projections to neocortex: axons from the dorsal and median raphe nuclei are differentially vulnerable to the neurotoxin pchloroamphetamine (PCA). Exp. Neurol. 1988; 102(1):23-36. [PubMed: 2846339]

Masaki E, Kawamura M, Kato F. Attenuation of gap-junction-mediated signaling facilitated anesthetic effect of sevoflurane in the central nervous system of rats. Anesth. Analg. 2004; 98(3):647-652. [PubMed: 14980913]

McGaughy J, Everitt BJ, Robbins TW, Sarter M. The role of cortical cholinergic afferent projections in cognition: impact of new selective immunotoxins. Behav. Brain Res. 2000; 115(2):251-263. [PubMed: 11000424]

McGaughy J, Ross RS, Eichenbaum H. Noradrenergic, but not cholinergic, deafferentation of prefrontal cortex impairs attentional set-shifting. Neuroscience. 2008; 153(1):63-71. [PubMed: 18355972]

McGaughy J, Sarter M. Sustained attention performance in rats with intracortical infusions of 192 IgGsaporin-induced cortical cholinergic deafferentation: effects of physostigmine and FG 7142. Behav. Neurosci. 1998; 112(6):1519-1525. [PubMed: 9926833]

McGaughy J, Sarter M. Effects of ovariectomy, 192 IgG-saporin-induced cortical cholinergic deafferentation, and administration of estradiol on sustained attention performance in rats. Behav. Neurosci. 1999; 113(6):1216-1232. [PubMed: 10636300]

McKinney M, Coyle JT, Hedreen JC. Topographic analysis of the innervation of the rat neocortex and hippocampus by the basal forebrain cholinergic system. J. Comp. Neurol. 1983; 217(1):103-121. [PubMed: 6875049]

McMillan PJ, White SS, Franklin A, Greenup JL, Leverenz JB, Raskind MA, Szot P. Differential response of the central noradrenergic nervous system to the loss of locus coeruleus neurons in Parkinson's disease and Alzheimer's disease. Brain Res. 2011; 1373:240-252. [PubMed: 21147074]

Mesulam MM, Mufson EJ, Levey AI, Wainer BH. Cholinergic innervation of cortex by the basal forebrain: cytochemistry and cortical connections of the septal area, diagonal band nuclei, nucleus basalis (substantia innominata), and hypothalamus in the rhesus monkey. J. Comp. Neurol. 1983; 214(2):170-197. [PubMed: 6841683]

Metherate R, Ashe JH. GABAergic suppression prevents the appearance and subsequent fatigue of an NMDA receptor-mediated potential in neocortex. Brain Res. 1995a; 699(2):221-230. [PubMed: 8616625]

Metherate R, Ashe JH. Synaptic interactions involving acetylcholine, glutamate, and GABA in rat auditory cortex. Exp. Brain Res. 1995b; 107(1):59-72. [PubMed: 8751063]

Metherate R, Cox CL, Ashe JH. Cellular bases of neocortical activation: modulation of neural oscillations by the nucleus basalis and endogenous acetylcholine. J. Neurosci. 1992; 12(12):47014711. [PubMed: 1361197]

Miguelez C, Grandoso L, Ugedo L. Locus coeruleus and dorsal raphe neuron activity and response to acute antidepressant administration in a rat model of Parkinson's disease. Int. J. Neuropsychopharmacol. 2011; 14(2):187-200. [PubMed: 20426885]

Moore RY, Halaris AE. Hippocampal innervation by serotonin neurons of the midbrain raphe in the rat. J. Comp. Neurol. 1975; 164(2):171-183. [PubMed: 52660]

Moore RY, Halaris AE, Jones BE. Serotonin neurons of the midbrain raphe: ascending projections. J. Comp. Neurol. 1978; 180(3):417-438. [PubMed: 77865]

Moxon KA, Devilbiss DM, Chapin JK, Waterhouse BD. Influence of norepinephrine on somatosensory neuronal responses in the rat thalamus: a combined modeling and in vivo multichannel, multi-neuron recording study. Brain Res. 2007; 1147:105-123. [PubMed: 17368434]

Murray EA, O'Doherty JP, Schoenbaum G. What we know and do not know about the functions of the orbitofrontal cortex after 20 years of cross-species studies. J. Neurosci. 2007; 27(31):8166-8169. [PubMed: 17670960] 
Newman LA, Darling J, McGaughy J. Atomoxetine reverses attentional deficits produced by noradrenergic deafferentation of medial prefrontal cortex. Psychopharmacology (Berlin). 2008; 200(1):39-50. [PubMed: 18568443]

Nicholson BJ, Weber PA, Cao F, Chang HC, Lampe P, Goldberg G. The molecular basis of selective permeability of connexins is complex and includes both size and charge. Braz. J. Med. Biol. Res. 2000; 33(4):369-378. [PubMed: 10775301]

Nieto-Escamez FA, Sanchez-Santed F, de Bruin JP. Cholinergic receptor blockade in prefrontal cortex and lesions of the nucleus basalis: implications for allocentric and egocentric spatial memory in rats. Behav. Brain Res. 2002; 134(1-2):93-112. [PubMed: 12191796]

O'Hearn E, Molliver ME. Organization of raphe-cortical projections in rat: a quantitative retrograde study. Brain Res. Bull. 1984; 13(6):709-726. [PubMed: 6099744]

Ongur D, Price JL. The organization of networks within the orbital and medial prefrontal cortex of rats, monkeys and humans. Cereb. Cortex. 2000; 10(3):206-219. [PubMed: 10731217]

Oyamada Y, Andrzejewski M, Muckenhoff K, Scheid P, Ballantyne D. Locus coeruleus neurones in vitro: $\mathrm{pH}$-sensitive oscillations of membrane potential in an electrically coupled network. Respir. Physiol. 1999; 118(2-3):131-147. [PubMed: 10647858]

Pang K, Williams MJ, Egeth PL, Olton DS. Nucleus basalis magnocellularis and attention: effects of muscimol infusions. Behav. Neurosci. 1993; 107(6):1031-1038. [PubMed: 8136056]

Passetti F, Chudasama Y, Robbins TW. The frontal cortex of the rat and visual attentional performance: dissociable functions of distinct medial prefrontal subregions. Cereb. Cortex. 2002; 12(12):1254-1268. [PubMed: 12427677]

Paxinos, G.; Watson, C. The Rat Brain, in Stereotaxic Coordinates. Academic Press; San Diego: 1997.

Price JL, Stern R. Individual cells in the nucleus basalis- diagonal band complex have restricted axonal projections to the cerebral cortex in the rat. Brain Res. 1983; 269(2):352-356. [PubMed: 6883087]

Rash JE, Olson CO, Davidson KG, Yasumura T, Kamasawa N, Nagy JI. Identification of connexin36 in gap junctions between neurons in rodent locus coeruleus. Neuroscience. 2007; 147(4):938-956. [PubMed: 17601673]

Robbins TW. Chemical neuromodulation of frontal-executive functions in humans and other animals. Exp. Brain Res. 2000; 133(1):130-138. [PubMed: 10933217]

Rushworth MF, Mars RB, Summerfield C. General mechanisms for making decisions. Curr. Opin. Neurobiol. 2009; 19(1):75-83. [PubMed: 19349160]

Sara SJ. The locus coeruleus and noradrenergic modulation of cognition. Nat. Rev. Neurosci. 2009; 10(3):211-223. [PubMed: 19190638]

Sarter M, Bruno JP. Cortical cholinergic inputs mediating arousal, attentional processing and dreaming: differential afferent regulation of the basal forebrain by telencephalic and brainstem afferents. Neuroscience. 2000; 95(4):933-952. [PubMed: 10682701]

Schoenbaum G, Saddoris MP, Stalnaker TA. Reconciling the roles of orbitofrontal cortex in reversal learning and the encoding of outcome expectancies. Ann. N. Y. Acad. Sci. 2007; 1121:320-335. [PubMed: 17698988]

Schofield BR. Retrograde axonal tracing with fluorescent markers. Curr. Protoc. Neurosci. (Chapter. 2008; 1 Unit 117.

Schofield BR, Schofield RM, Sorensen KA, Motts SD. On the use of retrograde tracers for identification of axon collaterals with multiple fluorescent retrograde tracers. Neuroscience. 2007; 146(2):773-783. [PubMed: 17379419]

Schultz W. Predictive reward signal of dopamine neurons. J. Neurophysiol. 1998; 80(1):1-27. [PubMed: 9658025]

Simpson KL, Altman DW, Wang L, Kirifides ML, Lin RC, Waterhouse BD. Lateralization and functional organization of the locus coeruleus projection to the trigeminal somatosensory pathway in rat. J. Comp. Neurol. 1997; 385(1):135-147. [PubMed: 9268121]

Simpson KL, Waterhouse BD, Lin RC. Origin, distribution, and morphology of galaninergic fibers in the rodent trigeminal system. J. Comp. Neurol. 1999; 411(3):524-534. [PubMed: 10413784] 
Simpson KL, Waterhouse BD, Lin RC. Characterization of neurochemically specific projections from the locus coeruleus with respect to somatosensory-related barrels. Anat. Rec. A Discoveries Mol. Cell. Evol. Biol. 2006; 288(2):166-173.

Sobel E, Corbett D. Axonal branching of ventral tegmental and raphe projections to the frontal cortex in the rat. Neurosci. Lett. 1984; 48(2):121-125. [PubMed: 6090994]

Sul JH, Kim PL, Huh N, Lee D, Jung MW. Distinct roles of rodent orbitofrontal and medial prefrontal cortex in decision making. Neuron. 2010; 66(3):449-460. [PubMed: 20471357]

Szot P, Miguelez C, White SS, Franklin A, Sikkema C, Wilkinson CW, Ugedo L, Raskind MA. A comprehensive analysis of the effect of DSP4 on the locus coeruleus noradrenergic system in the rat. Neuroscience. 2010; 166(1):279-291. [PubMed: 20045445]

UniProt. The universal protein resource (UniProt) 2009. Nucleic Acids Res. 2009; 37(Database issue):D169-D174. [PubMed: 18836194]

Van Bockstaele EJ, Biswas A, Pickel VM. Topography of serotonin neurons in the dorsal raphe nucleus that send axon collaterals to the rat prefrontal cortex and nucleus accumbens. Brain Res. 1993; 624(1-2):188-198. [PubMed: 8252391]

Van Bockstaele EJ, Garcia-Hernandez F, Fox K, Alvarez VA, Williams JT. Expression of connexins during development and following manipulation of afferent input in the rat locus coeruleus. Neurochem. Int. 2004; 45(2-3):421-428. [PubMed: 15145556]

Vercelli A, Repici M, Garbossa D, Grimaldi A. Recent techniques for tracing pathways in the central nervous system of developing and adult mammals. Brain Res. Bull. 2000; 51(1):11-28. [PubMed: 10654576]

Vertes RP. A PHA-L analysis of ascending projections of the dorsal raphe nucleus in the rat. J. Comp. Neurol. 1991; 313(4):643-668. [PubMed: 1783685]

Villar MJ, Vitale ML, Hokfelt T, Verhofstad AA. Dorsal raphe serotoninergic branching neurons projecting both to the lateral geniculate body and superior colliculus: a combined retrograde tracing-immunohistochemical study in the rat. J. Comp. Neurol. 1988; 277(1):126-140. [PubMed: 3198794]

Vucetic Z, Totoki K, Schoch H, Whitaker KW, Hill-Smith T, Lucki I, Reyes TM. Early life protein restriction alters dopamine circuitry. Neuroscience. 2010; 168(2):359-370. [PubMed: 20394806]

Wang M, Pei L, Fletcher PJ, Kapur S, Seeman P, Liu F. Schizophrenia, amphetamine-induced sensitized state and acute amphetamine exposure all show a common alteration: increased dopamine D2 receptor dimerization. Mol. Brain. 2010; 3:25. [PubMed: 20813060]

Waterhouse BD, Border B, Wahl L, Mihailoff GA. Topographic organization of rat locus coeruleus and dorsal raphe nuclei: distribution of cells projecting to visual system structures. J. Comp. Neurol. 1993; 336(3):345-361. [PubMed: 8263226]

Waterhouse BD, Lin CS, Burne RA, Woodward DJ. The distribution of neocortical projection neurons in the locus coeruleus. J. Comp. Neurol. 1983; 217(4):418-131. [PubMed: 6886061]

Waterhouse BD, Mihailoff GA, Baack JC, Woodward DJ. Topographical distribution of dorsal and median raphe neurons projecting to motor, sensorimotor, and visual cortical areas in the rat. J. Comp. Neurol. 1986; 249(4):460-476. 478-81. [PubMed: 3528236]

Weber PA, Chang HC, Spaeth KE, Nitsche JM, Nicholson BJ. The permeability of gap junction channels to probes of different size is dependent on connexin composition and permeant-pore affinities. Biophys. J. 2004; 87(2):958-973. [PubMed: 15298902]

Weinshenker D. Functional consequences of locus coeruleus degeneration in Alzheimer's disease. Curr. Alzheimer Res. 2008; 5(3):342-345. [PubMed: 18537547]

Wenk GL. The nucleus basalis magnocellularis cholinergic system: one hundred years of progress. Neurobiol. Learn. Mem. 1997; 67(2):85-95. [PubMed: 9075237]

Wilson MA, Molliver ME. The organization of serotonergic projections to cerebral cortex in primates: retrograde transport studies. Neuroscience. 1991; 44(3):555-570. [PubMed: 1721683]

Yasui Y, Masaki E, Kato F. Sevoflurane directly excites locus coeruleus neurons of hats. Anesthesiology. 2007; 107(6):992-1002. [PubMed: 18043068]

Yeager M, Nicholson BJ. Structure of gap junction intercellular channels. Curr. Opin. Struct. Biol. 1996; 6(2):183-192. [PubMed: 8728651] 
A

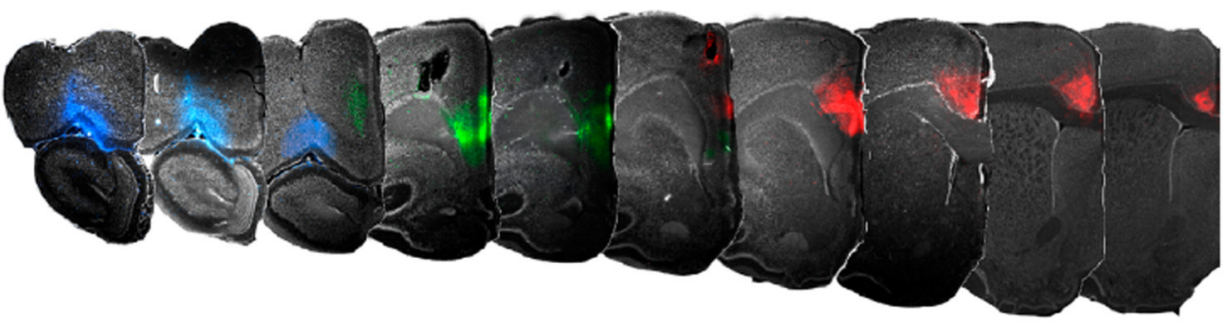

B
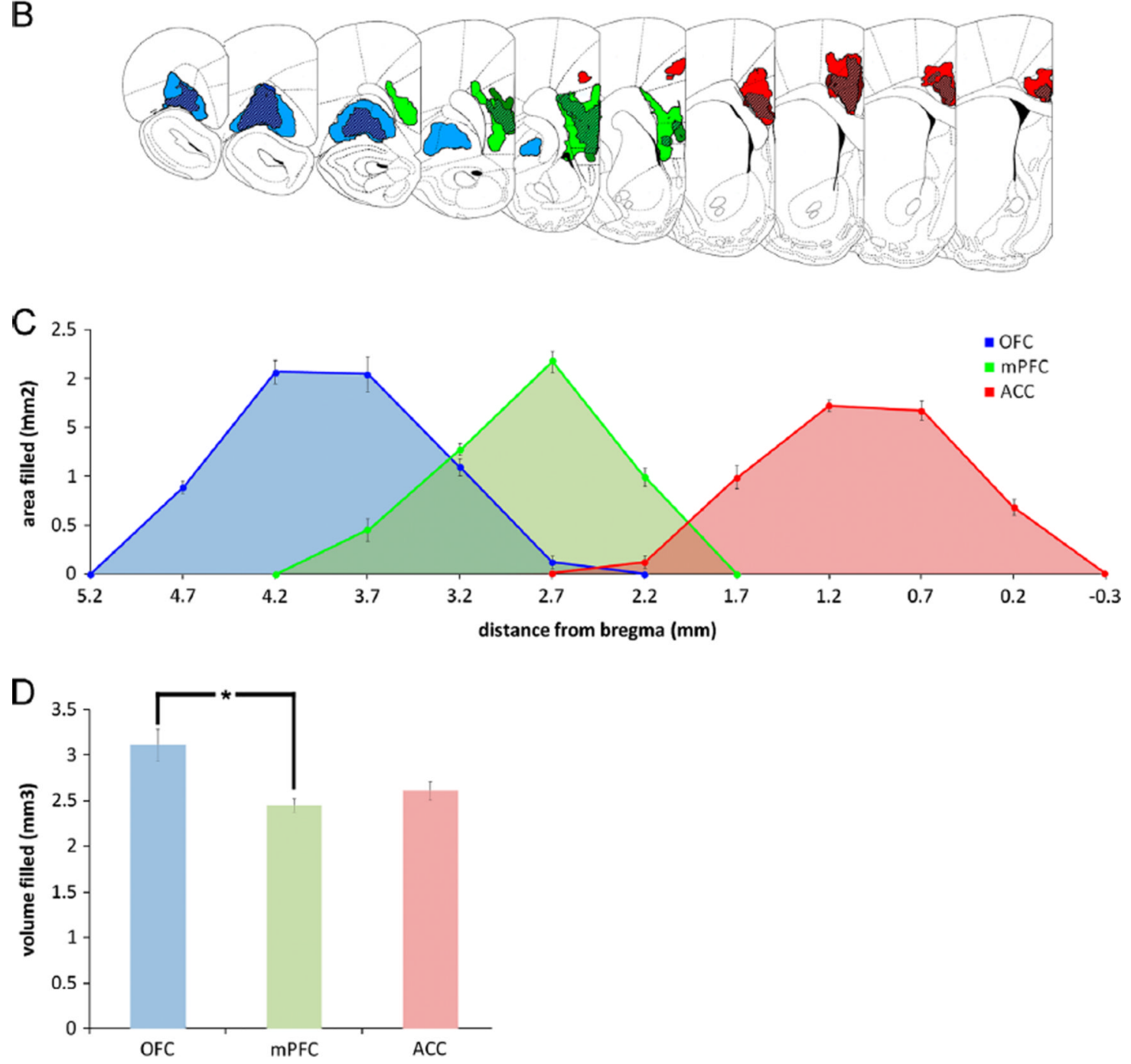

Fig. 1.

(A) Representative photomicrographs of injection sites in OFC (blue fluorescence), mPFC (green fluorescence) and ACC (red fluorescence) from a single animal. A schematic representation of the rostrocaudal extent of injection sites was created using data pooled from all subjects $(n=9)$, i.e. the largest and smallest injections at each level are illustrated. The area of the tissue in each section that contained residual fluorescence was calculated with ImageJ software. The boundaries of the largest (lighter color) and smallest (darker color) areas containing fluorescence in each section are shown in B. The mean area filled with residual fluorescence for each PFC subregion was calculated across all 9 animals and was plotted as a function of each section's distance from bregma, and is shown in $\mathrm{C}$. 
Individual photomicrographs of sections in A and schematics in B align with the values along the $\mathrm{X}$ axis of $\mathrm{C}$. The area under each curve in $\mathrm{C}$ was calculated to obtain an estimate of the volume of tissue in each PFC subregion that was filled with tracer; these values are shown in D. A significantly greater volume of OFC was filled than $\mathrm{mPFC}(p<0.05)$. 

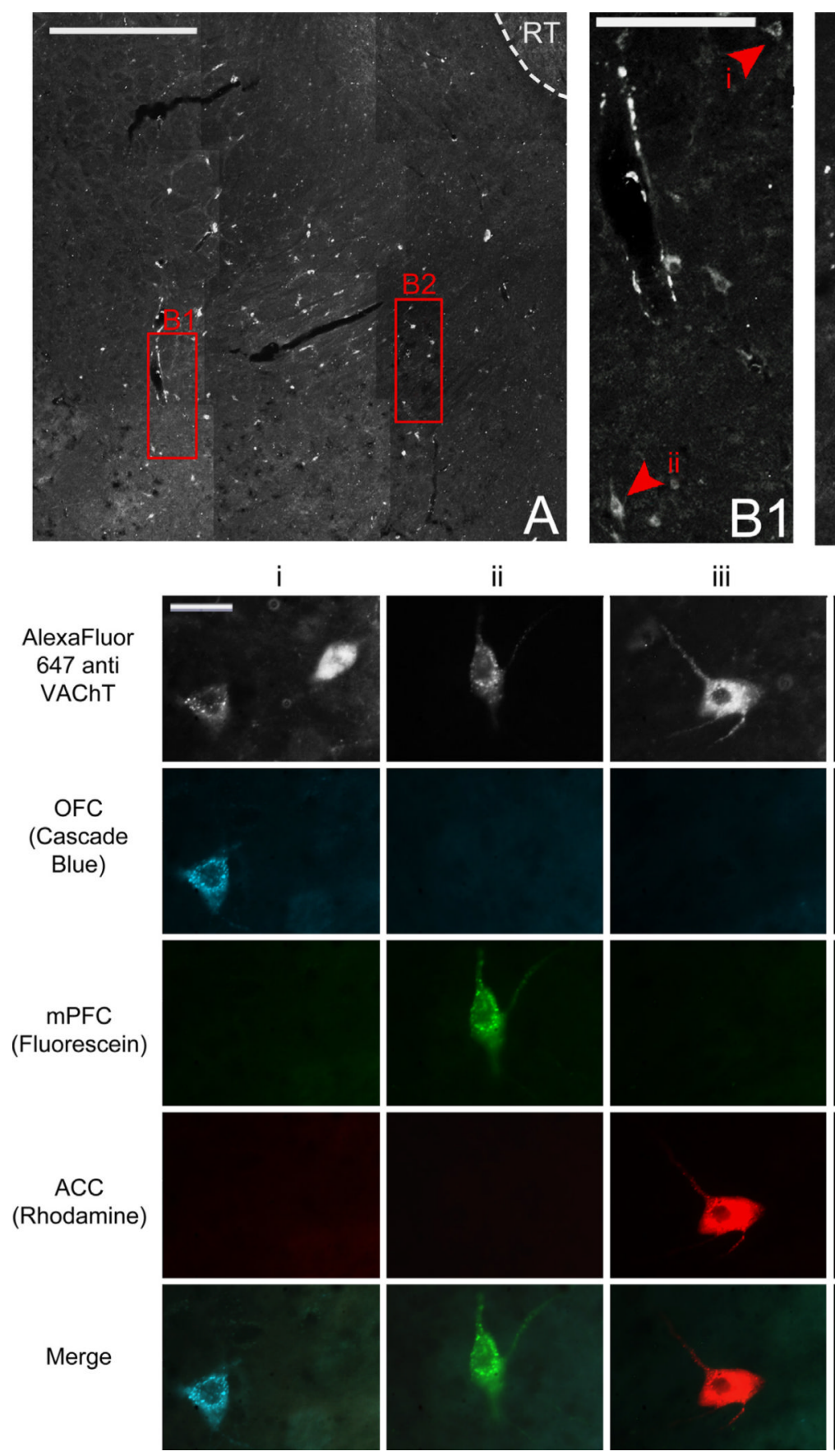
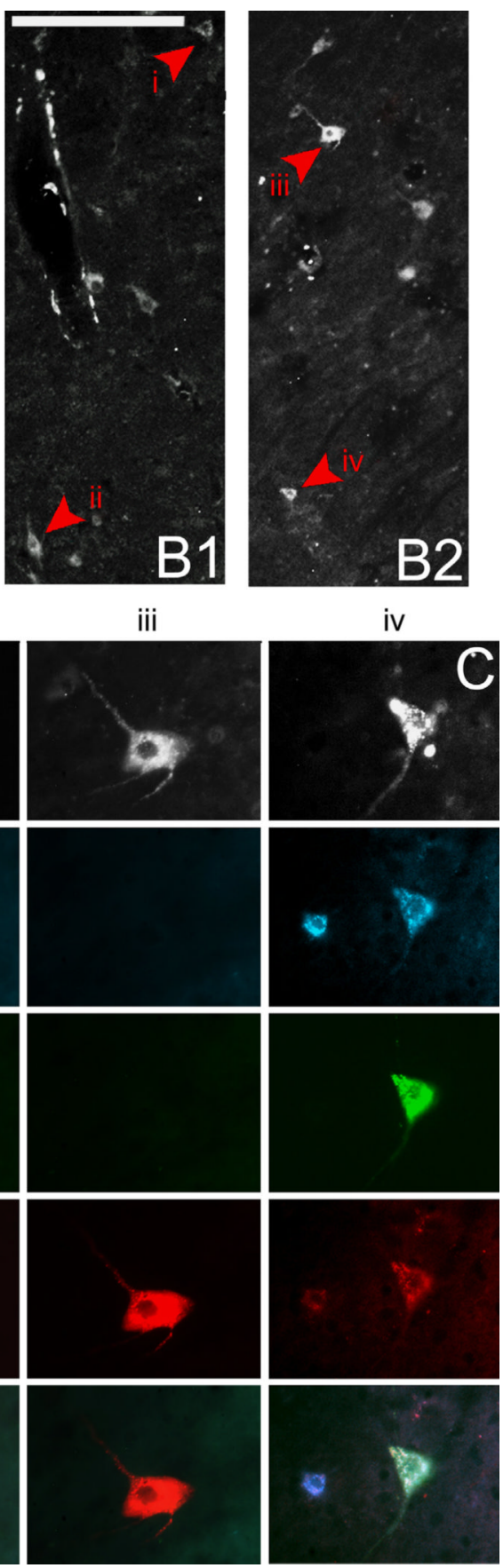

Fig. 2.

(A) Low power image of NB through fluorescent filter to show VAChT immunoreactivity. Scale bar $=400 \mu \mathrm{m}$. (B1 and B2) Higher power images of areas represented in left and right red boxes in (A), respectively. Arrowheads and roman numerals indicate locations of cells represented in C. Scale bar=100 $\mu \mathrm{m}$. (C) High power images of individual retrogradely labeled putative cholinergic neurons indicated by arrowheads in B through various fluorescence filters to show tracers with which they were labeled and therefore to which subregions of PFC they project. Individual columns show the same cell through various fluorescence filters; individual rows show different cells through the same fluorescence filter. Scale bar=20 $\mu \mathrm{m}$. NB, Nucleus basalis; RT, reticular nucleus of thalamus; VAChT, 
vesicular acetylcholine transporter; OFC, orbitofrontal cortex; mPFC, medial prefrontal cortex; ACC, anterior cingulate cortex. 

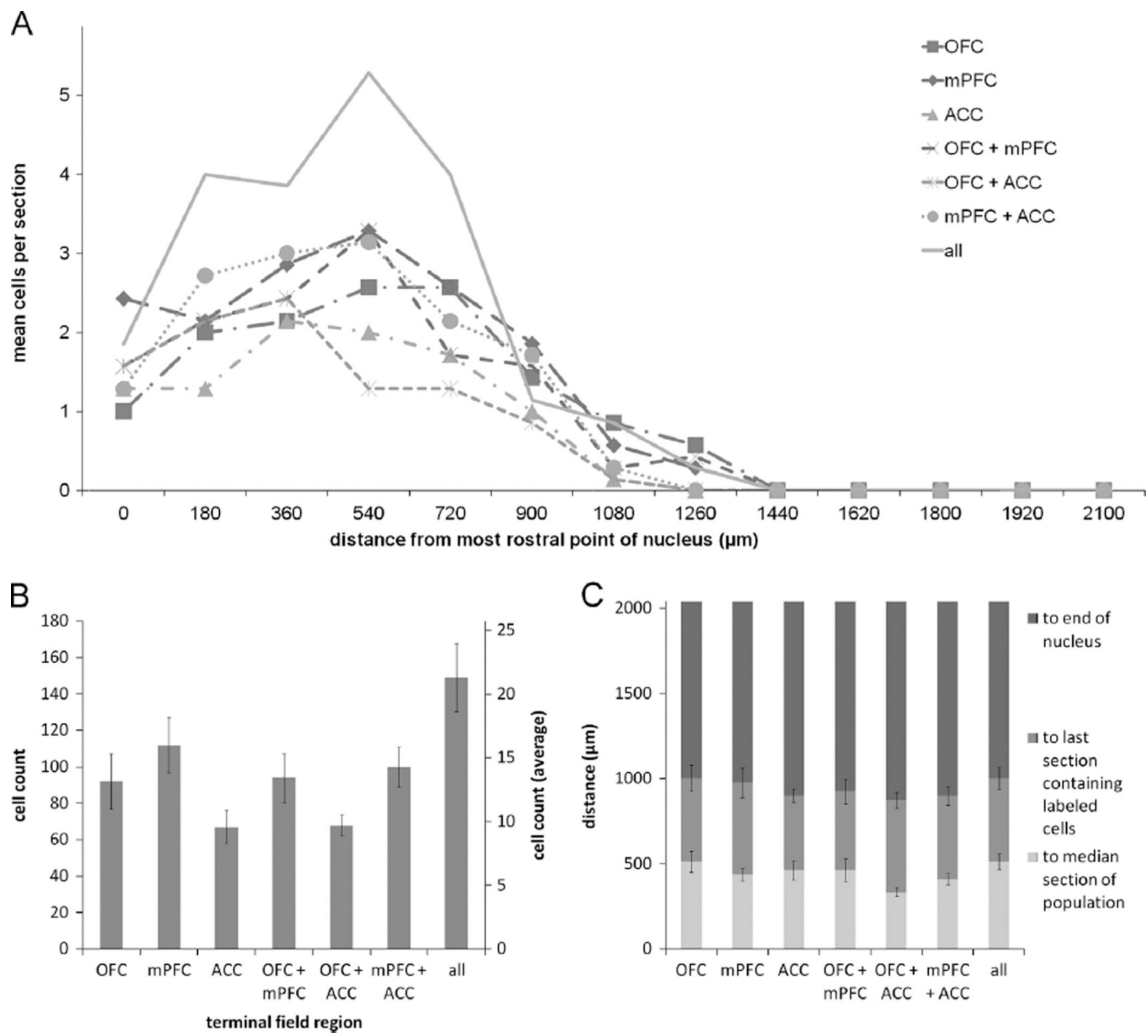

Fig. 3.

(A) Mean number of retrogradely labeled NB cells per section per rat according to rostrocaudal position for the various populations of projection neurons. (B) Cumulative (left axis) and mean \pm SEM (right axis) counts of retrogradely labeled neurons projecting to each possible combination of terminal fields from all animals $(n=7)$. (C) Distance to the median section, last section which contained retrogradely labeled neurons, and the end of the nucleus \pm SEM for the various populations of projection neurons. Note that roughly one-half of the nucleus, i.e. the caudal end, is devoid of retrograde labeling. NB, Nucleus basalis; VAChT, vesicular acetylcholine transporter; OFC, orbitofrontal cortex; mPFC, medial prefrontal cortex; ACC, anterior cingulate cortex. 

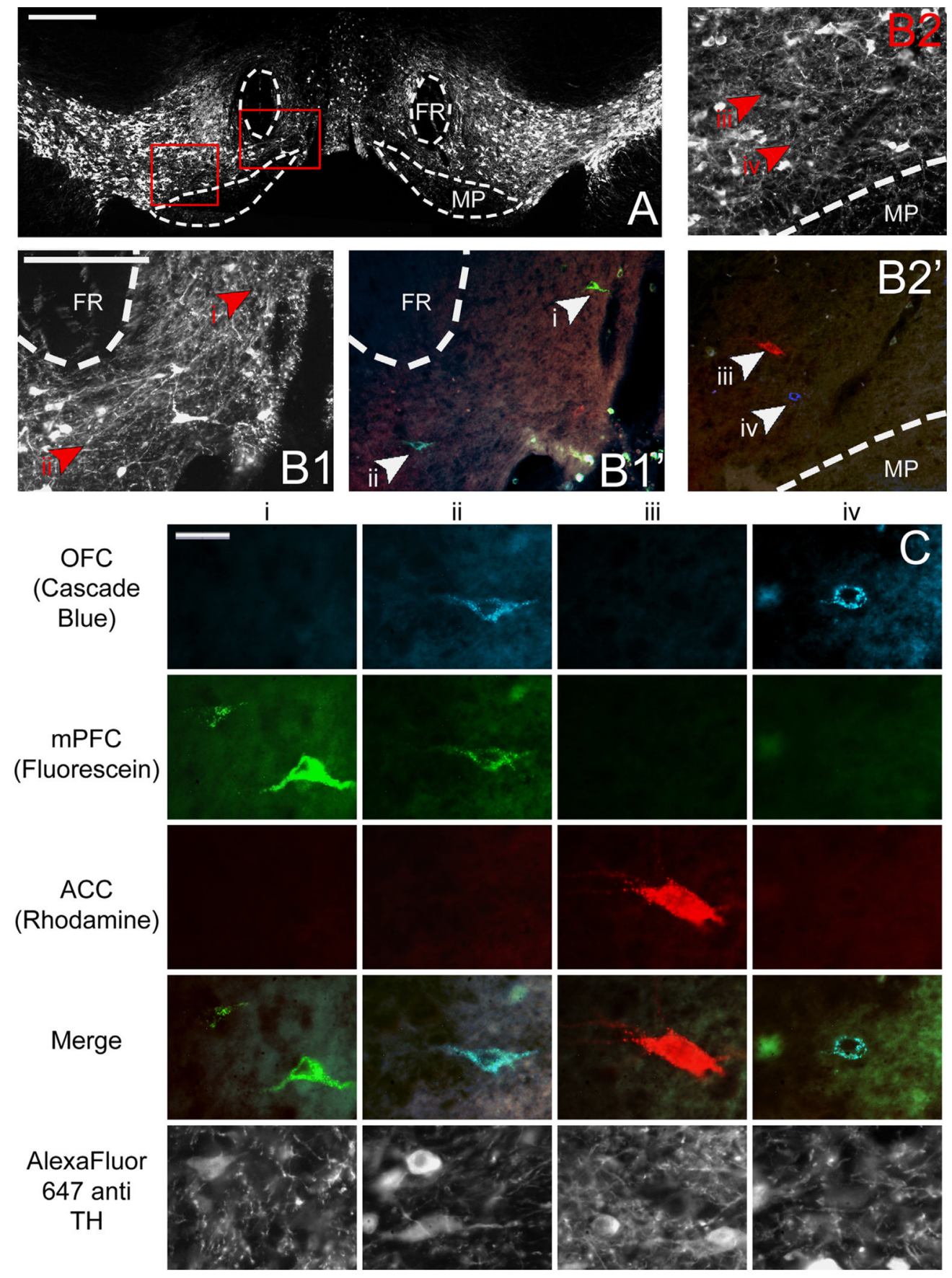

Fig. 4.

(A) Low power image of VTA through fluorescent filter to show TH immunoreactivity. Scale bar $=400 \mu \mathrm{m}$. (B1) Higher magnification of areas enclosed by right red box in (A) through fluorescence filter to show TH immunoreactivity (left, B1) and merged fluorescence filters (right, B12) to show retrogradely labeled cells. (B2) Higher magnification of areas enclosed by left red box in (A) through fluorescence filter to show TH immunoreactivity (top, Bl) and merged fluorescence filters (bottom, B12) to show retrogradely labeled cells. Arrowheads and roman numerals indicate locations of cells represented in (C). Scale bars for $\mathrm{B}=200 \mu \mathrm{m}$. (C) High power images of individual retrogradely labeled VTA neurons indicated by arrowheads in B through various fluorescence filters to show tracers with which 
they were labeled and therefore to which subregions of PFC they project. Individual columns show the same cell through various fluorescence filters; individual rows show different cells through the same fluorescence filter. Scale bar $=20 \mu \mathrm{m}$. VTA, ventral tegmental area; FR, fasciculus retroflexus; MP, mammilary peduncle; TH, tyrosine hydroxylase; $\mathrm{OFC}$, orbitofrontal cortex; $\mathrm{mPFC}$, medial prefrontal cortex; ACC, anterior cingulate cortex. 


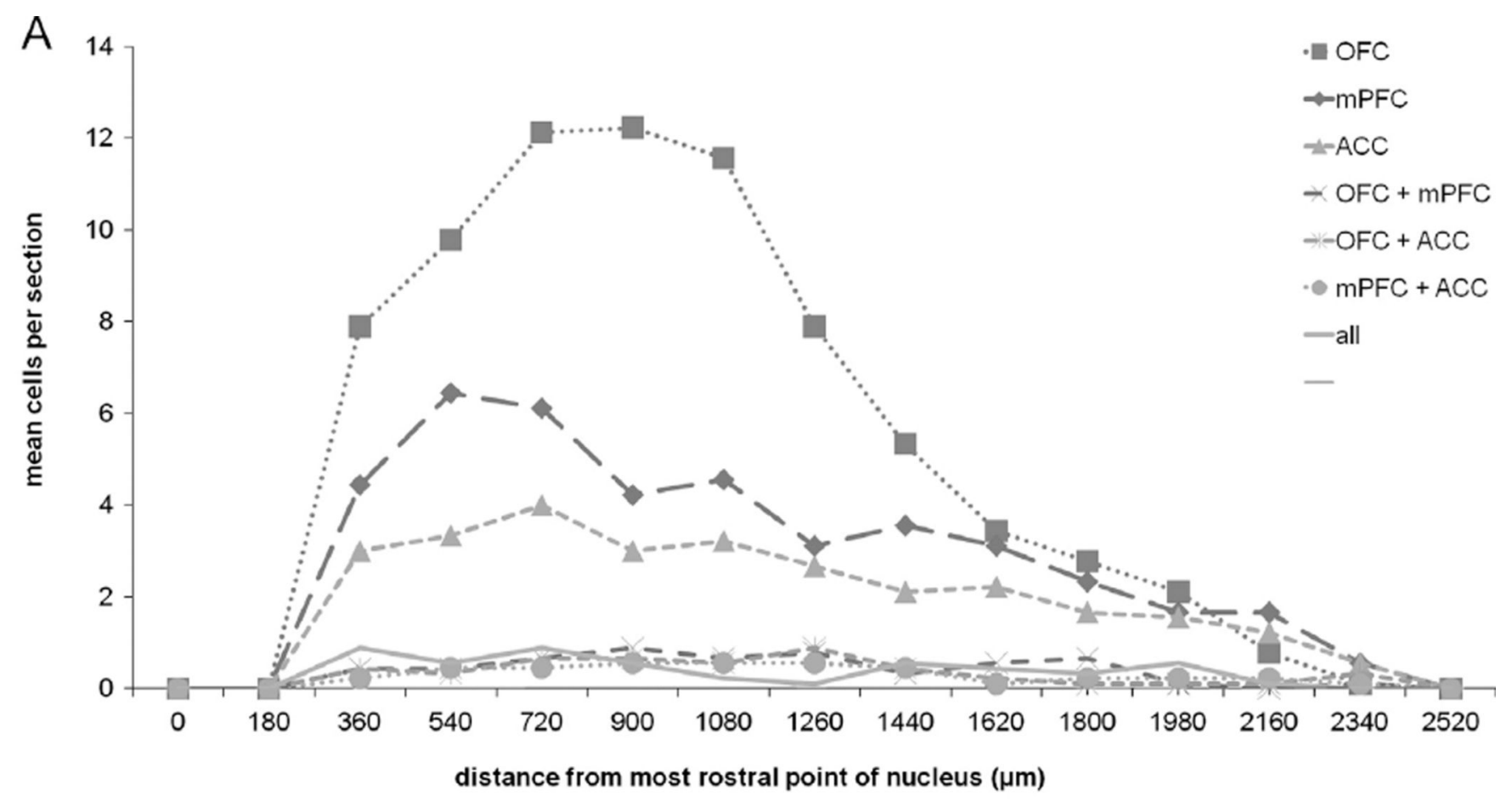

B

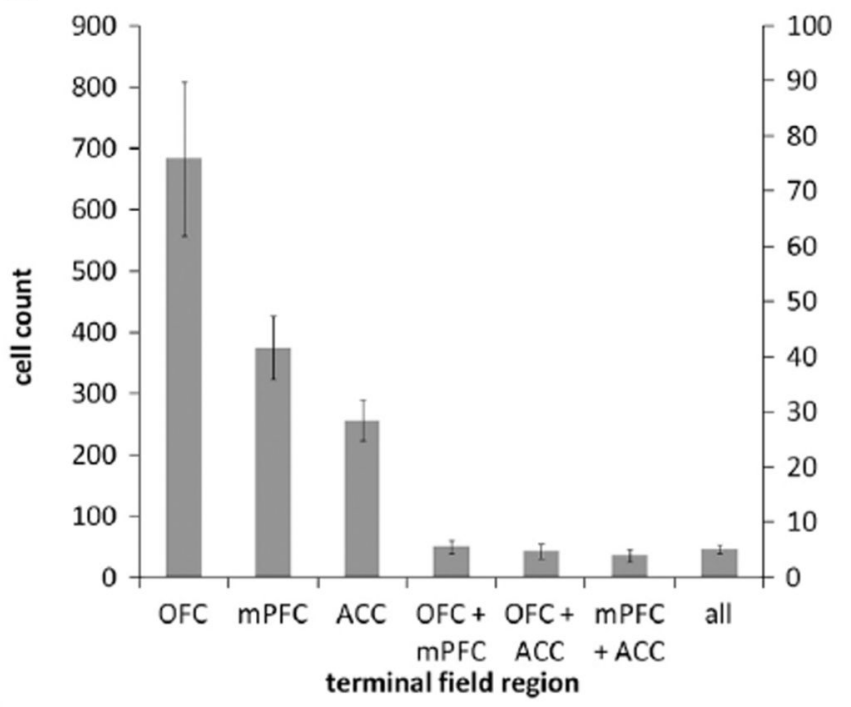

C

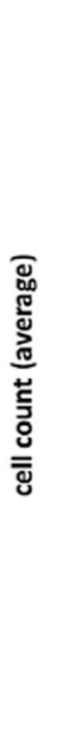

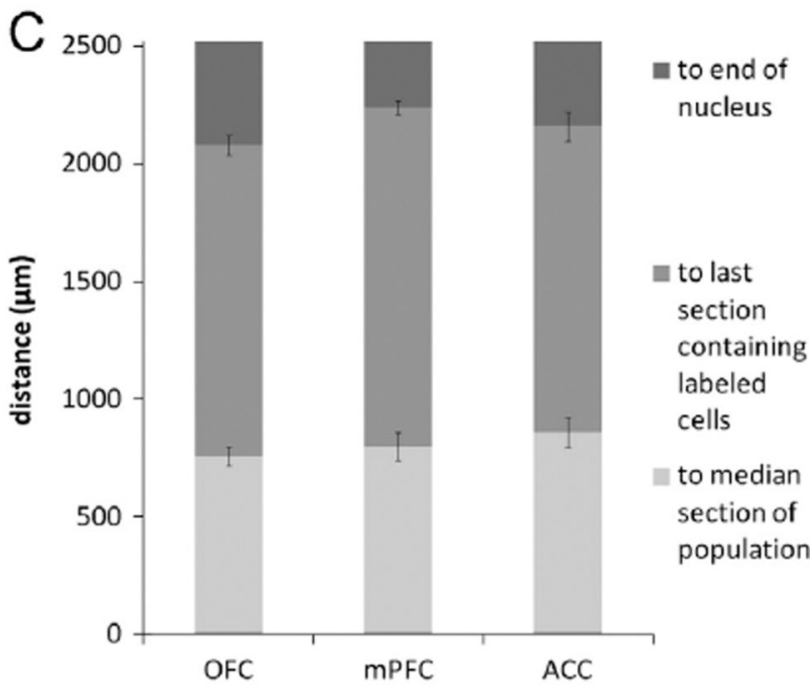

Fig. 5.

(A) Mean number of retrogradely labeled VTA cells per section per rat according to rostrocaudal position for the various populations of projection neurons. (B) Cumulative (left axis) and mean \pm SEM (right axis) counts of retrogradely labeled neurons projecting to each possible combination of terminal fields from all animals $(n=9)$. (C) Distance to the median section, last section which contained retrogradely labeled neurons, and the end of the nucleus \pm SEM for the three populations of singly-projecting neurons. VTA, ventral tegmental area; TH, tyrosine hydroxylase; OFC, orbitofrontal cortex; mPFC, medial prefrontal cortex; ACC, anterior cingulate cortex.

Brain Res. Author manuscript; available in PMC 2014 July 19. 

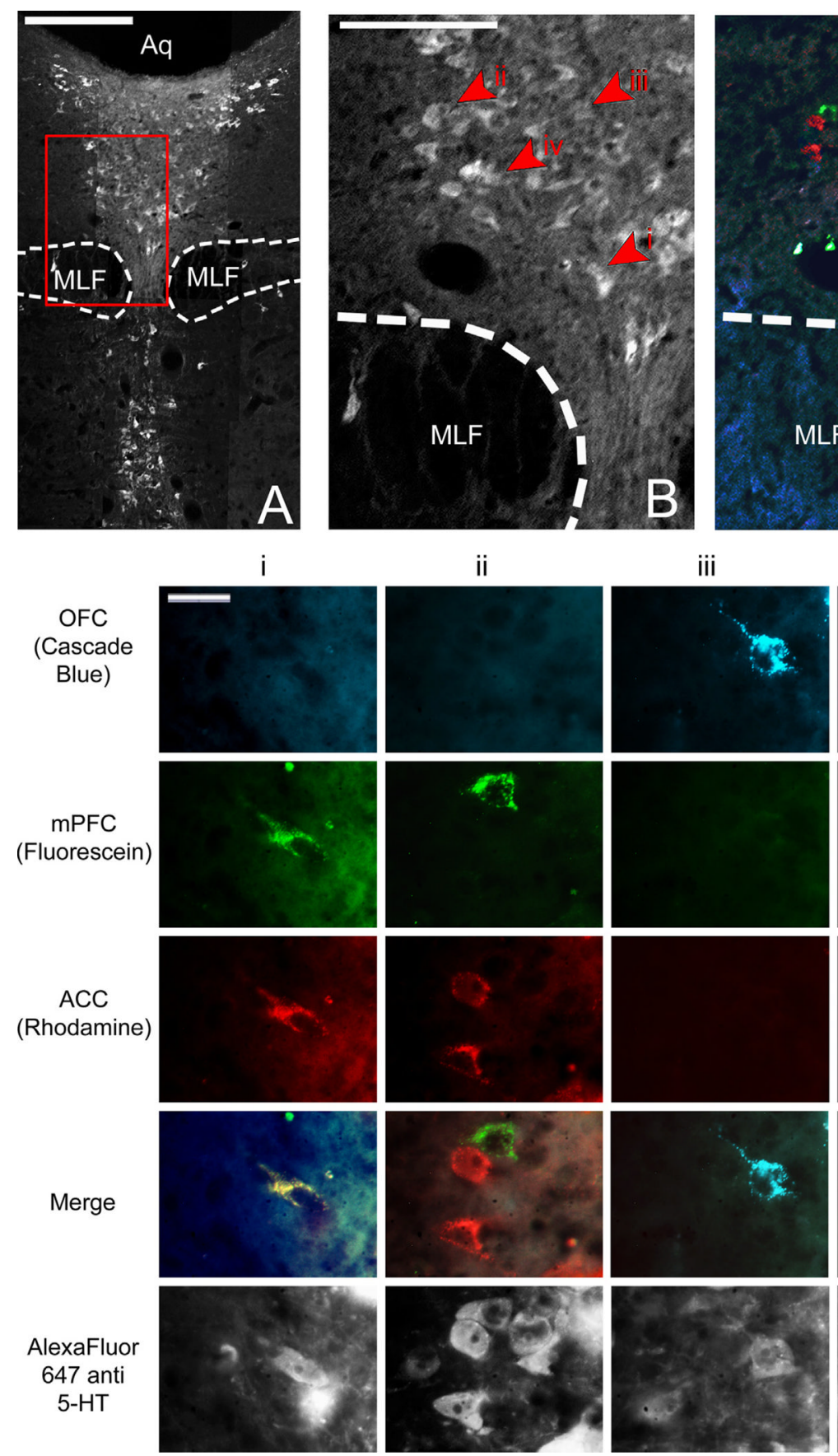

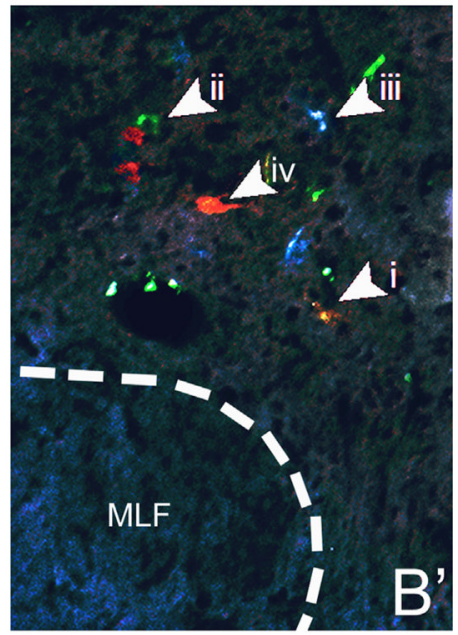

iv
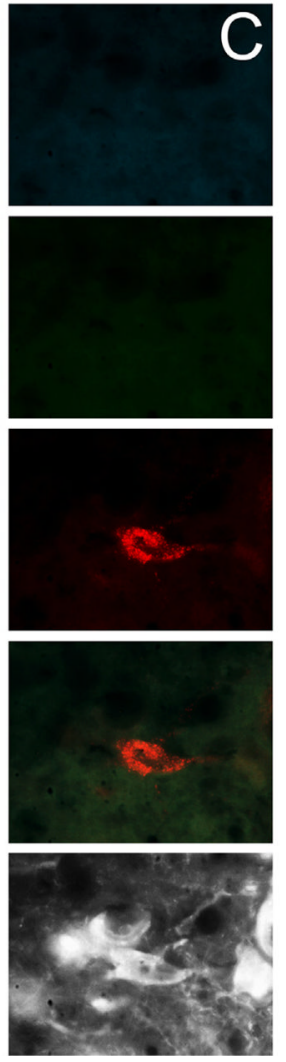

Fig. 6.

(A) Low power image of DRN through fluorescent filter to show 5HT immunoreactivity. Scale bar $=400 \mu \mathrm{m}$. (B) Higher magnification of area enclosed by red box in (A) through fluorescence filter to show 5HT immunoreactivity (left, B) and merged fluorescence filters to show retrogradely labeled cells (right, B2). Arrowheads and roman numerals indicate locations of cells represented in (C). Scale bar=200 $\mu \mathrm{m}$. (C) High power images of individual retrogradely labeled DRN neurons indicated by arrowheads in B through various fluorescence filters to show tracers with which they were labeled and therefore to which subregions of PFC they project. Individual columns show the same cell through various fluorescence filters; individual rows show different cells through the same fluorescence 
filter. Scale bar=20 $\mu \mathrm{m}$. DRN, dorsal raphe nucleus; MLF, medial longitudinal fasiculus, Aq, cerebral aqueduct; 5HT, serotonin; OFC, orbitofrontal cortex; mPFC, medial prefrontal cortex; ACC, anterior cingulate cortex. 

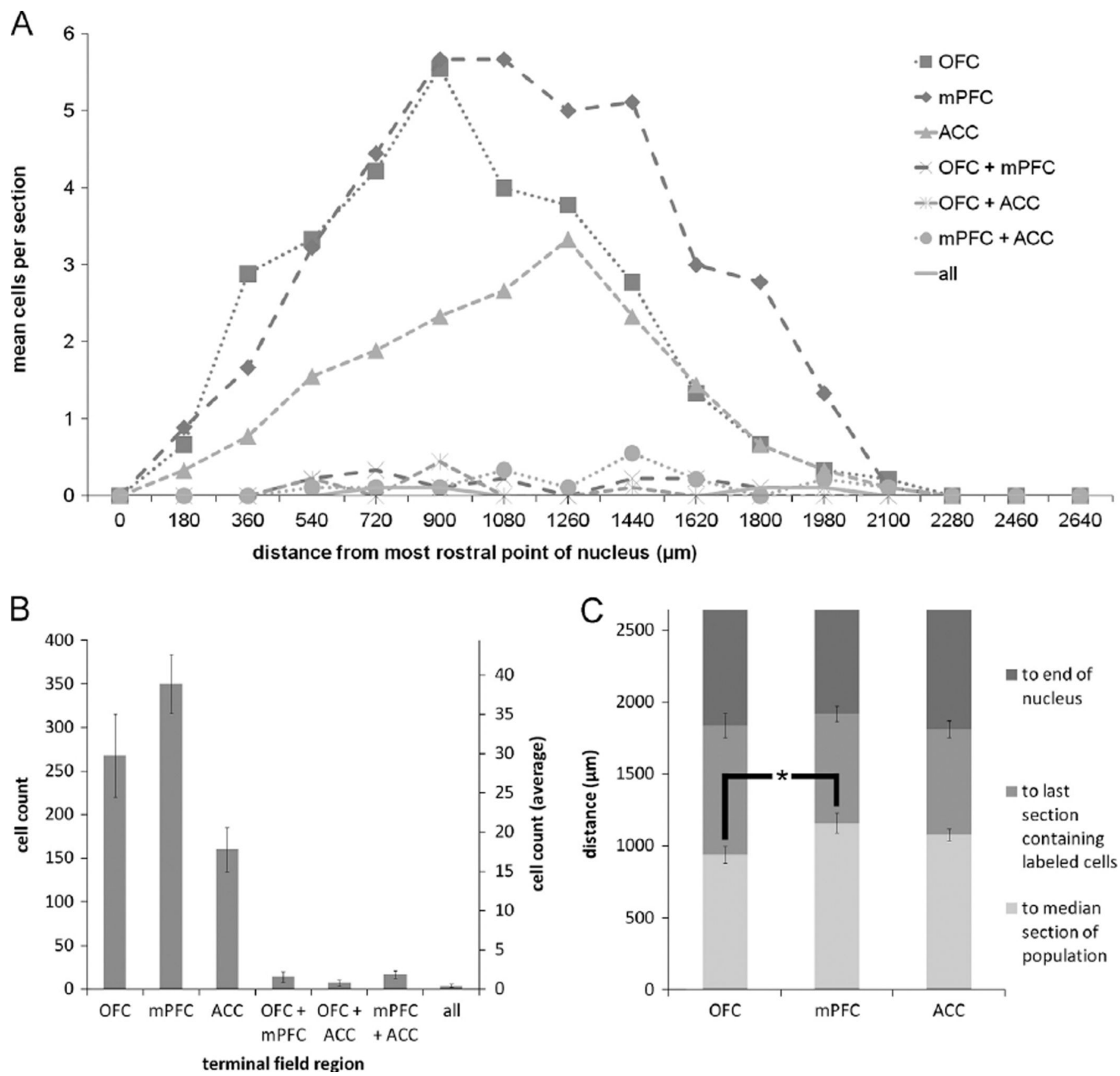

Fig. 7.

(A) Mean number of retrogradely labeled DRN cells per section per rat according to rostrocaudal position for the various populations of projection neurons. (B) Cumulative (left axis) and mean \pm SEM (right axis) counts of retrogradely labeled neurons projecting to each possible combination of terminal fields from all animals $(n=9)$. (C) Distance to the median section, last section which contained retrogradely labeled neurons, and the end of the nucleus \pm SEM for the three populations of singly-projecting neurons. Note that roughly one-third to one-quarter of the nucleus, i.e. the caudal tail, is devoid of retrograde labeling. OFC projection cells in DRN cluster significantly more rostrally than do MPFC projection cells $(p<0.05)$. DRN, dorsal raphe nucleus; 5HT, serotonin; OFC, orbitofrontal cortex; mPFC, medial prefrontal cortex; ACC, anterior cingulate cortex. 

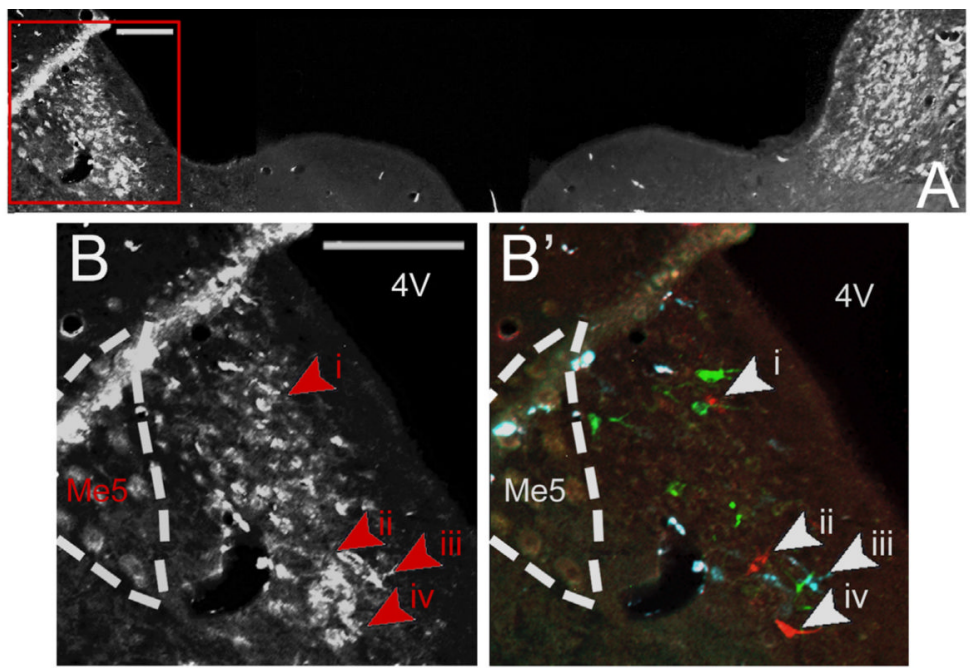

i

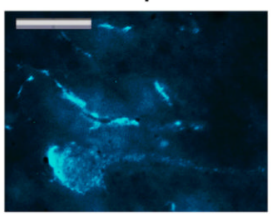

ii
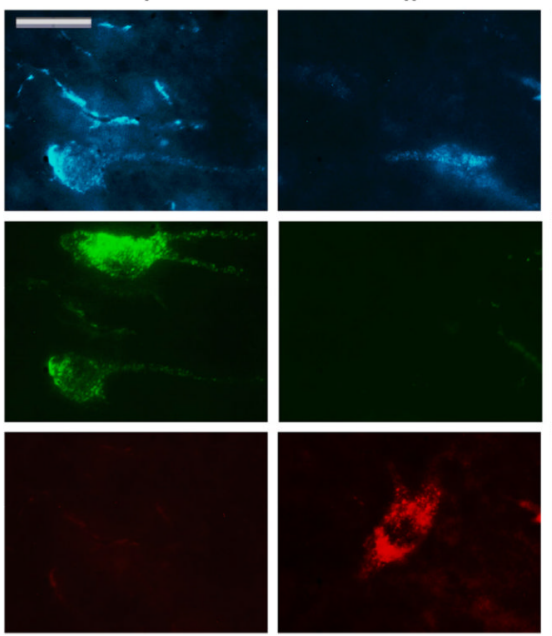

ACC

(Rhodamine)
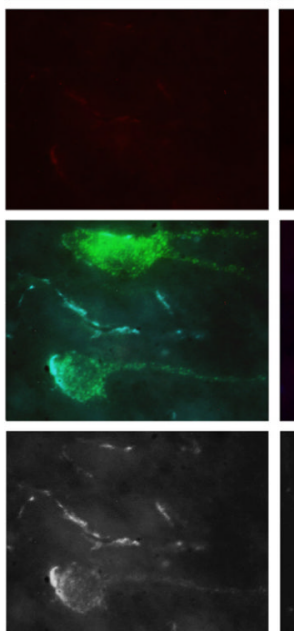

iii
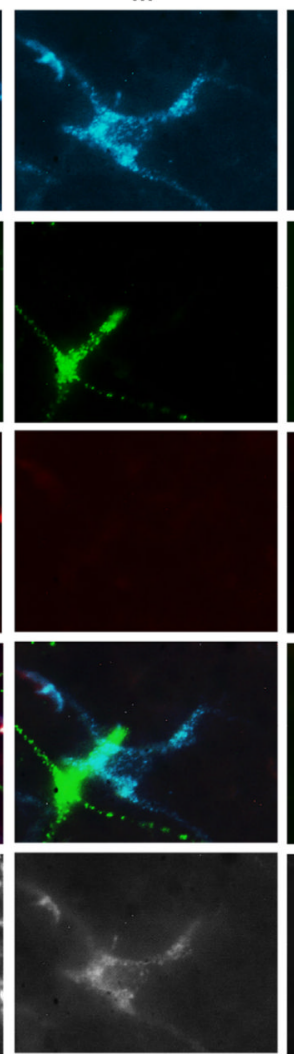

iv
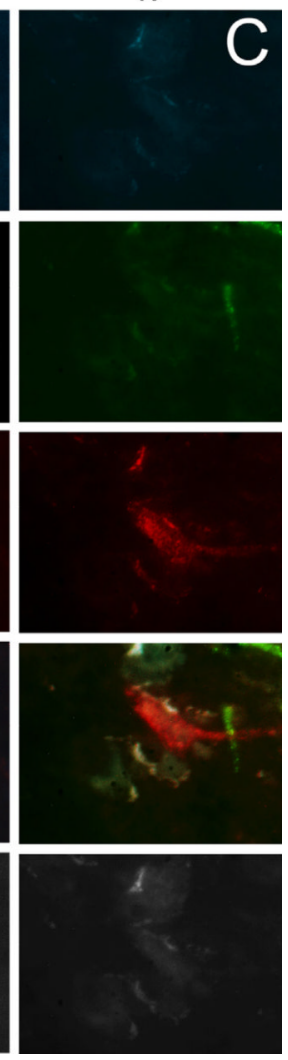

Fig. 8.

(A) Low power image of LC through fluorescent filter to show galanin immunoreactivity. The area enclosed by the red box is shown at higher magnification in $\mathrm{B}$, and through merged fluorescence channels in $\mathrm{B} 2$ to show locations of retrogradely labeled cells shown in $\mathrm{C}$. Scale bar in A and B=200 $\mu \mathrm{m}$. (C) High power images of individual retrogradely labeled LC neurons indicated by arrowheads in $\mathrm{B}$ through various fluorescence filters to show tracers with which they were labeled and therefore to which subregions of PFC they project Individual columns show the same cell through various fluorescence filters; individual rows show different cells through the same fluorescence filter. Scale bar $=20 \mu \mathrm{m}$. LC, locus 
coeruleus; Me5, mesencephalic trigeminal nucleus; 4V, fourth ventricle; OFC, orbitofrontal cortex; mPFC, medial prefrontal cortex; ACC, anterior cingulate cortex. 

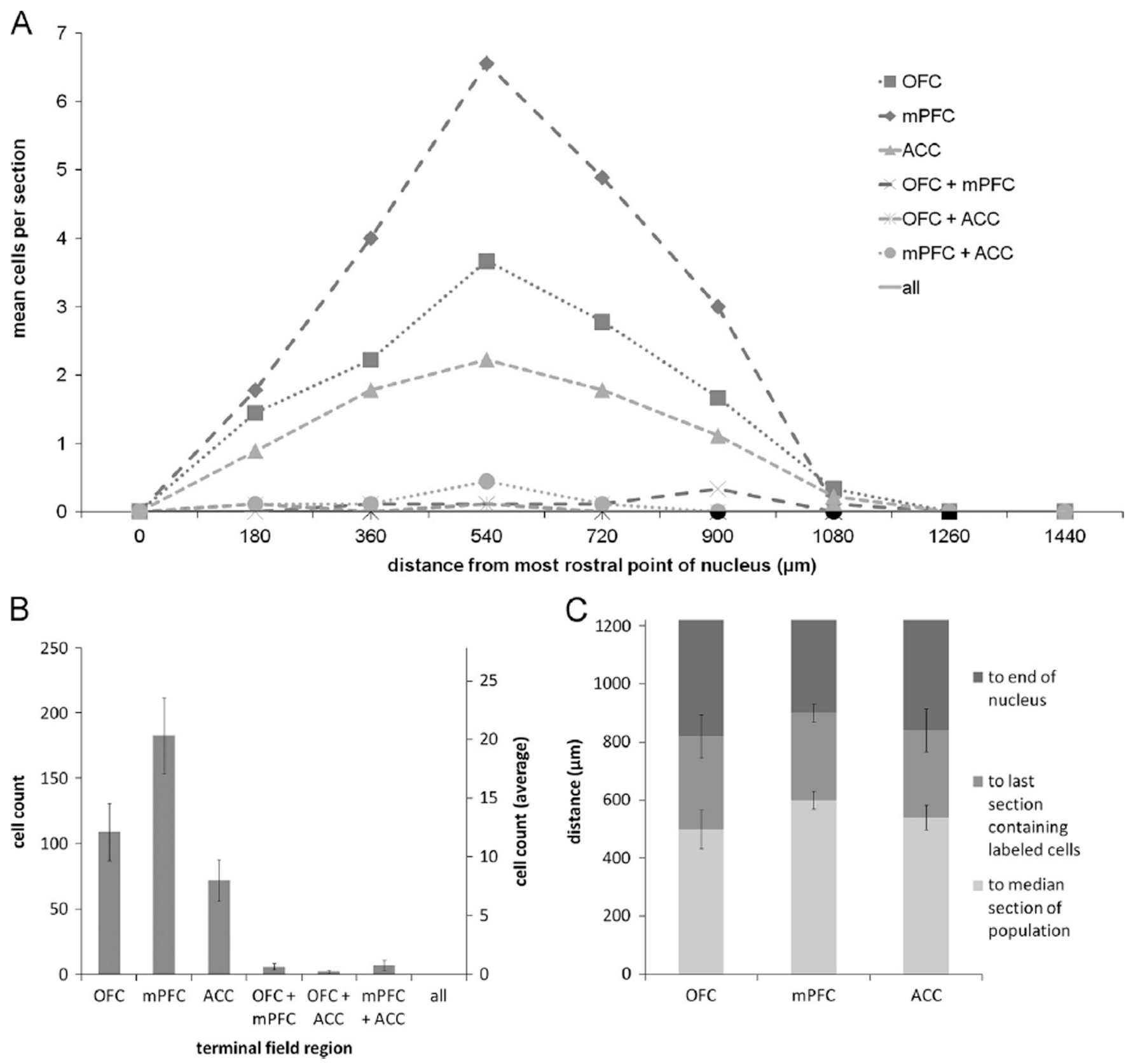

Fig. 9.

(A) Mean number of retrogradely labeled LC cells per section per rat according to rostrocaudal position for the various populations of projection neurons. (B) Cumulative (left axis) and mean \pm SEM (right axis) counts of retrogradely labeled neurons projecting to each possible combination of terminal fields from all animals $(n=9)$. (C) Distance to the median section, last section which contained retrogradely labeled neurons, and the end of the nucleus \pm SEM for the three populations of singly-projecting neurons. Note that the caudal one-quarter of the nucleus is devoid of retrograde labeling. LC, locus coeruleus; OFC, orbitofrontal cortex; mPFC, medial prefrontal cortex; ACC, anterior cingulate cortex. 


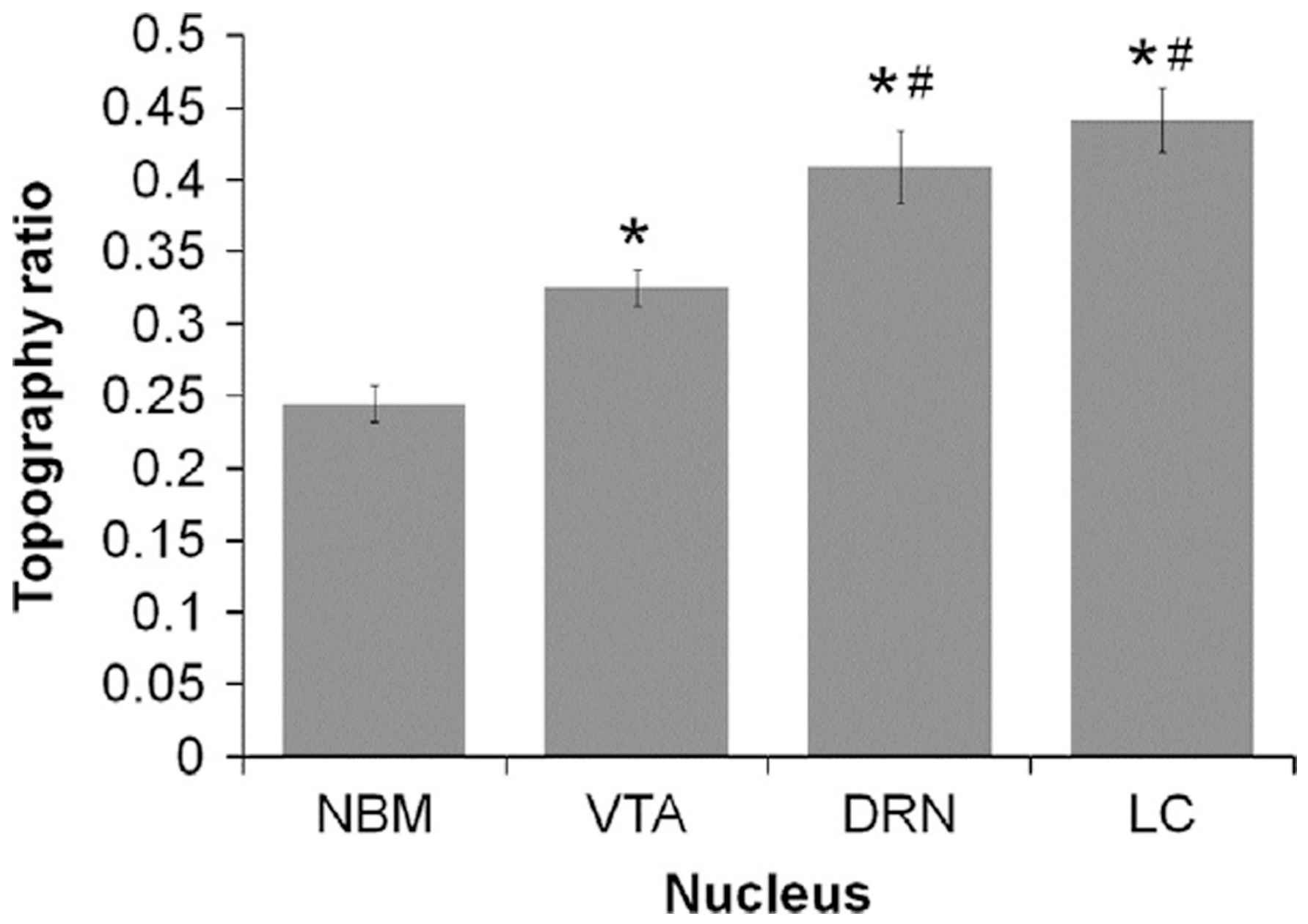

Fig. 10.

Distance to the median section for all populations of cells relative to the absolute length of each nucleus. Values closer to zero indicate that cells were clustered more rostrally, while values closer to one indicate that cells clustered more caudally. *: significantly different from NB; \#: significantly different than VTA. NB: Nucleus basalis; VTA: ventral tegmental area; DRN: dorsal raphe nucleus; LC: locus coeruleus. 


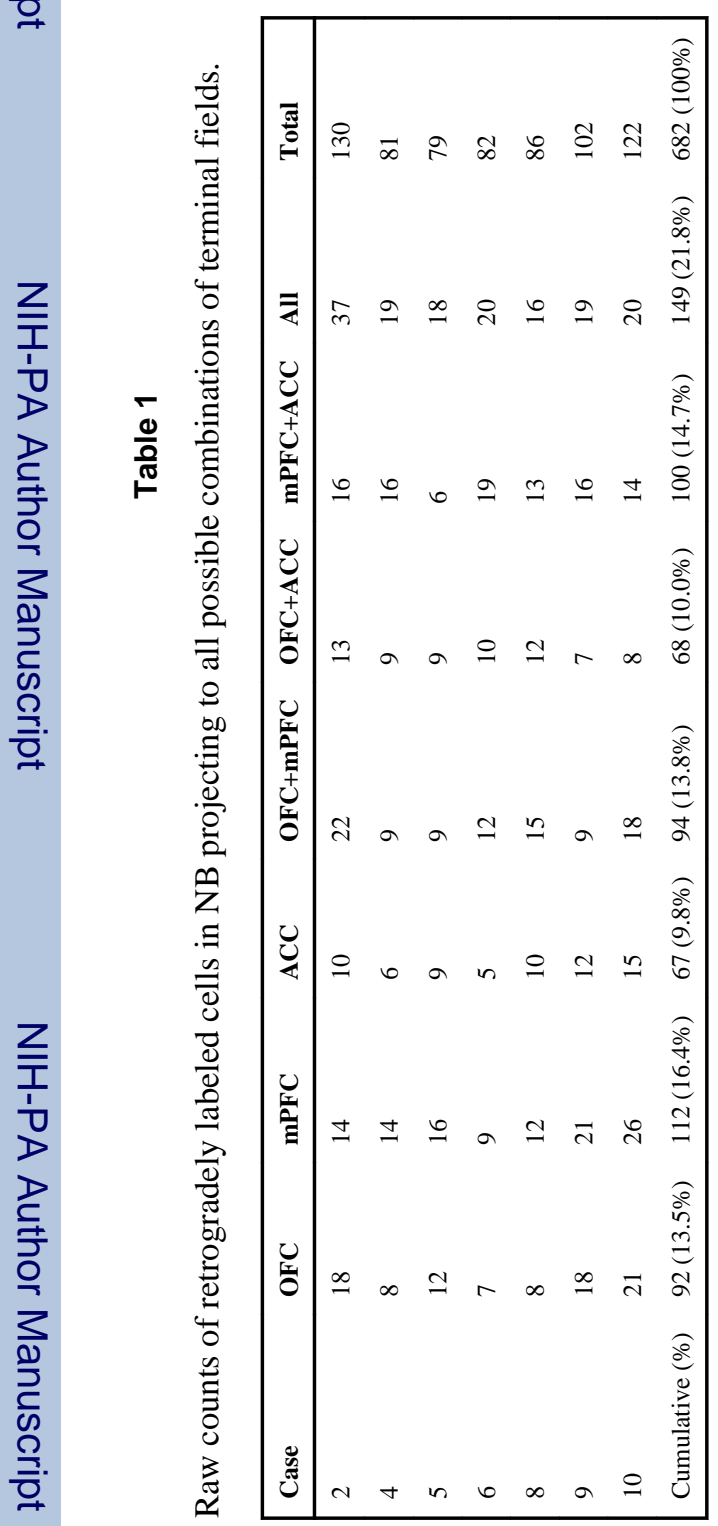

Brain Res. Author manuscript; available in PMC 2014 July 19. 


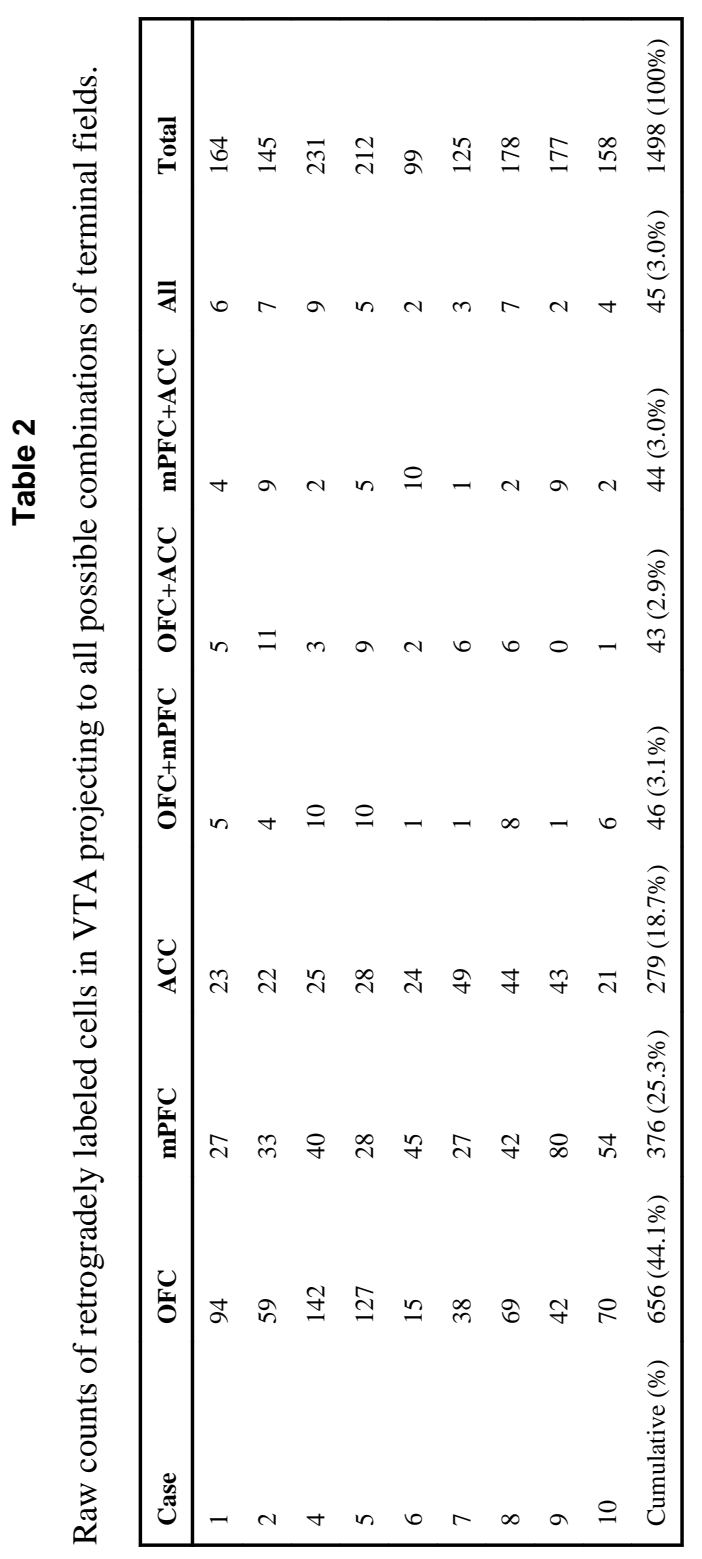

Brain Res. Author manuscript; available in PMC 2014 July 19. 


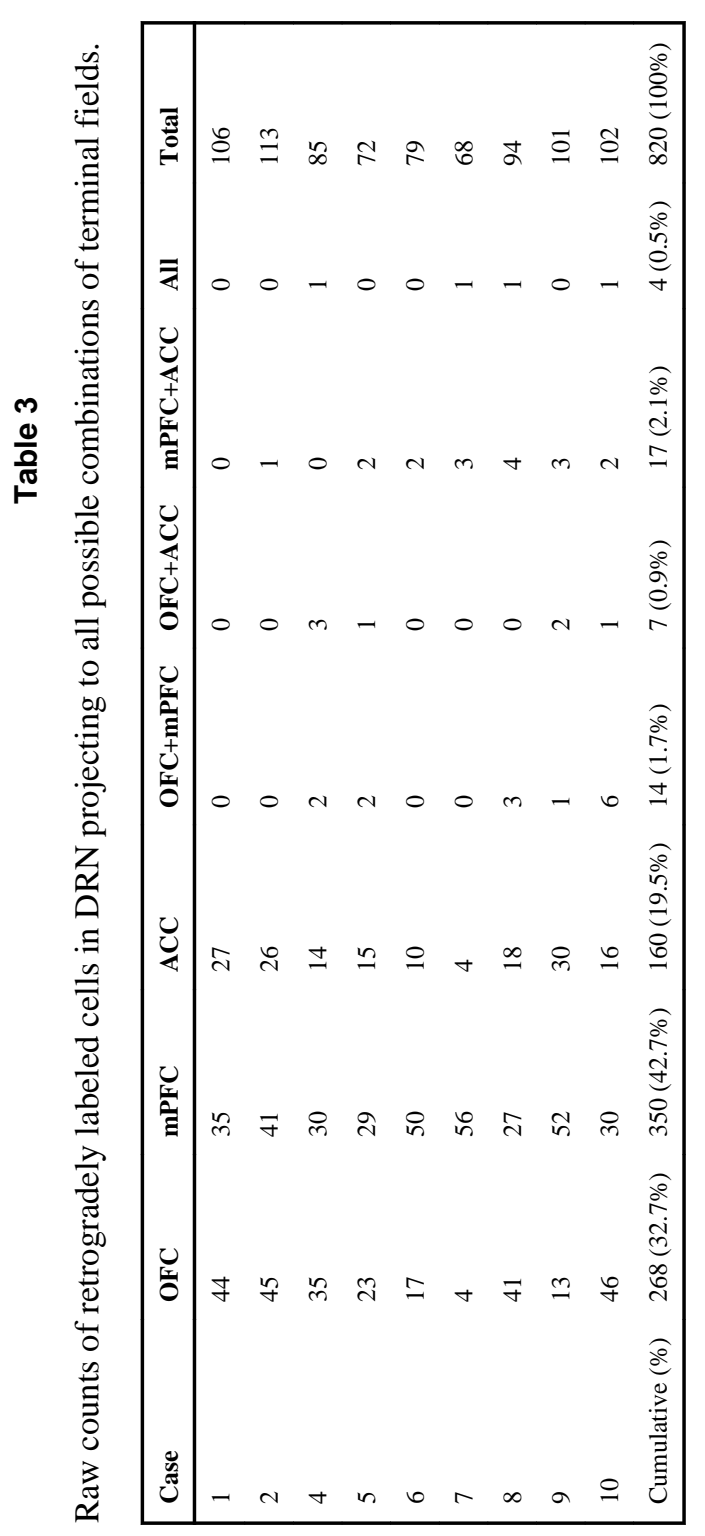

Brain Res. Author manuscript; available in PMC 2014 July 19. 


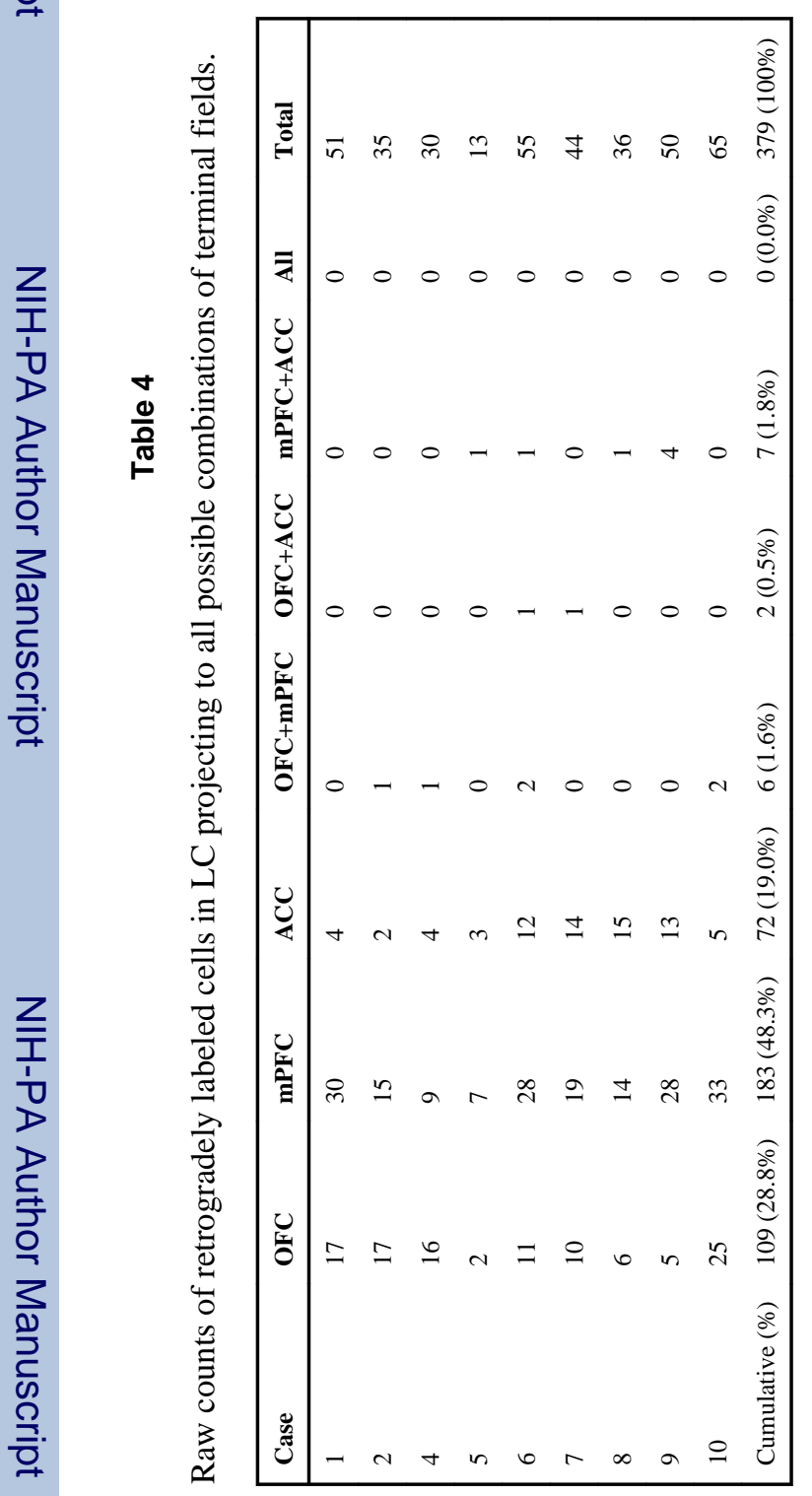

Brain Res. Author manuscript; available in PMC 2014 July 19. 